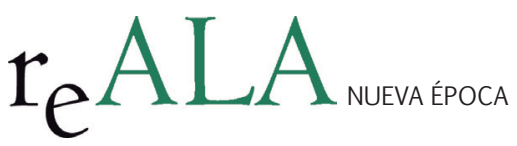

REALA, n 3, enero-junio 2015 ISSN: 1989-8975

DOI: http://dx.doi.org/10.24965/reala.voi3.10247

\title{
El alcalde del liberalismo moderado, teoría y práctica (1845-1868)
}

\author{
Ana Cristina Pérez Rodríguez \\ anacristinpr@yahoo.es
}

\begin{abstract}
Resumen
El presente artículo describe las competencias del alcalde del liberalismo moderado en sus dos vertientes: teórica y práctica. La parte teórica procede del análisis de la Ley de Organización y Atribuciones de los Ayuntamientos del 8 de enero de 1845, como ley fundamental para la administración local y para la consolidación de un nuevo tipo de alcalde jefe de la administración local, separado del resto del consistorio y nombrado por el gobierno entre los regidores elegidos. Este alcalde contaba con dos tipos de atribuciones: las delegadas por el gobierno y referidas fundamentalmente al mantenimiento del orden y la salud públicos y las derivadas de su carácter electivo y centradas en la administración de los recursos de los pueblos y el fortalecimiento económico.

La parte práctica procede del estudio del Ayuntamiento de Santiago de Compostela entre 1844 y 1868 a través de sus actas de sesiones, presupuestos, bandos municipales, oficios y la documentación correspondiente a la recaudación de impuestos públicos y trata de ofrecer una visión real del alcance político y de gestión del alcalde moderado.
\end{abstract}

Palabras clave

Alcalde, ayuntamiento, liberalismo moderado, Santiago de Compostela.

\section{The mayor of moderate liberalism: theory and practise (1845-1868)}

Abstract

This paper, describes the responsibilities and powers of the mayor during de moderate liberalism period from two different but complement points of view: theory and practice. The theoretical part results from the analysis of the Law of Organization and Attributions of the Town halls of January 8, 1845 as the most important law to the local administration and to the consolidation of a new type of mayor, chief of the local administration, separated from the council and appointed by the government between the elected councillors. This mayor had to two types of attributions: those delegated from the government and referred fundamentally to the public maintenance of the order and the health, and those derived from its elective character, that were focused on the administration of the resources of towns and their economic strengthening.

The practical part of the manuscript cames from the study of the city council of Santiago de Compostela between 1844 and 1868 though the minutes of the assembly, budgets, public announcements, correspondence and the public tax collection documentation, trying to offer an actual extent of the political outreach and management of the moderate mayor.

Key words

Mayor, city council, moderate liberalism, Santiago de Compostela. 


\section{INTRODUCCIÓN}

El presente trabajo tiene como objeto de estudio un tipo de alcalde muy determinado, el alcalde moderado creado por la Ley de Organización y Atribuciones de los Ayuntamientos del 8 de enero de 1845, vigente hasta la Revolución de 1868. El otorgamiento de ciertas libertades a la Nación reflejadas en el Estatuto Real de 1834, los derechos y libertades recogidos en la Constitución de 1837 y el nombramiento de los alcaldes por el Gobierno bajo la ley municipal de junio de 1840 fueron el caldo de cultivo sobre el que se produciŕa no solo la división del bando liberal en progresistas y moderados, sino también la creación de un nuevo modelo municipal por parte de éstos últimos que estaría vigente casi tres décadas'.

El 8 de enero de 1845, varios meses antes de proclamar una nueva Constitución y casi sin haberse instalado en el poder, los moderados aprueban la Ley de Organización y Atribuciones de los Ayuntamientos, una ley que fortalecería enormemente el poder de los alcaldes en los pueblos a la vez que les sujetaría firmemente al gobierno de turno. El objetivo era el control político administrativo de los pueblos y aunque en un principio hubo enormes resistencias por parte de los mayores contribuyentes locales, éstos acabaron por aceptar el modelo de jerarquía administrativa a cambio de controlar por sí mismos la gestión de los impuestos a través de las juntas de repartimiento.

\section{EL ALUMBRAMIENTO DEL ALCALDE MODERADO: CONTEXTO POLÍTICO ADMINISTRATIVO}

Los moderados acceden al poder en mayo de 1844 de la mano del General Narváez, inaugurando la Década Moderada (1844-1854) y dando paso a una serie de reformas como la fiscal de Mon y Santillán de 1845, la supresión de la Milicia Nacional ciudadana y la creación de un cuerpo profesional como la Guardia Civil, la suspensión de las leyes desamortizadoras y una reforma estructural de las administraciones que abarcaba el ámbito provincial y municipal ${ }^{2}$.

Desde un primer momento se plantea la necesidad de reformar la Constitución de 1837 o sustituirla por una nueva y así el 23 de mayo de 1845 se promulgó una nueva Constitución conocida como la Constitución de los moderados o de $1845^{3}$. Jordi Solé Tura, Eliseo Aja, González Ares o Font de Mora4, la valoran como una Constitución absolutamente distinta de la de 1837, pero otros historiadores como Tomás Villarroya o Sánchez Agesta creen que fue únicamente una revisión, aunque el último autor insiste en que esa revisión fue sustancial y profunda 5 . Al margen de este debate es necesario reconocer que existían grandes diferencias entre ambas constituciones, ya que mientras la de 1837 proclamaba la soberanía absoluta de la Nación, la de 1845 instauró una soberanía compartida entre las Cortes y la Monarquía debido al temor que sentían hacia las clases populares y su participación en política ${ }^{6}$. Este principio constituyó el núcleo de la nueva norma fundamental y marcó el funcionamiento institucional de toda la administración del país, restringiendo al máximo la participación del pueblo en las instituciones de gobierno y de la administración?.

La Constitución de 1845 se caracterizó también por reforzar el ejecutivo en detrimento del Parlamento, hecho que permitió anular numerosas iniciativas legislativas y cerrar las Cortes por Decreto cuando se consideraba necesario ${ }^{8}$. Esta práctica ya había sido ensayada en los ayuntamientos mediante la publicación de la Ley de Organización y Atribuciones de los Ayuntamientos de 1845, diseñándolos como meros entes administrativos que podían ser suspendidos en cualquier momento y que contaban con muy pocas atribuciones. A pesar de sus

1 La construcción del municipio liberal fue una tarea lenta y ardua marcada por lentos períodos constitucionales 1812-1814 y 1820-23, así como por los intentos del absolutismo de continuar perviviendo a través de las instituciones liberales. Ver Pérez Rodríguez, A.C. (2014). Pág. $52-66$.

2 Los moderados no eran un partido cohesionado, sino que en su interior convivían doceañistas, exaltados, afrancesados, absolutistas, carlistas, etc. El grupo principal eran los doctrinarios teniendo a su izquierda a los puritanos liderados por Francisco Pacheco y Nicomedes Pastor Díaz y caracterizados por ser partidarios de la reconciliación con el ala menos radical del progresismo. En el ala más a la derecha estaban los neoabsolutistas encabezados por el Marqués de Viluma y tendentes a una alianza con el carlismo. Así, no fue una etapa estable pues se sucedieron muchos gobiernos, hasta 14 distintos, pero fue un período de signo moderado donde los propietarios llevaban las riendas del gobierno y la política y establecían sus criterios como agenda política.

3 FONT DE MORA, T. (1991). No todos los moderados pretendían una reforma de la Constitución sino que muchos como Pacheco, Pastor Díaz o Isturiz preferían adaptarse a la situación porque un cambio en el Gobierno no tenía que implicar una renovación de la Ley fundamental de la Nación sino que era en el marco de la Constitución donde debían realizarse los cambios políticos.

4 AJA, E.; SOLÉ TURA, J. (1988).; FONT DE MORA, T. (1991).; GONZÁLEZ ARES, J.A. (1997).; SOLÉ TURA, J. (1975).

5 SÁNCHEZ AGESTA, L. (1984).; SOLÉ TURA, J. y AJA, E. (1988).; TOMÁS VILLARROYA, J. (1981).

6 Sánchez Agesta aprecia que la compartimentación de la Soberanía iba más allá de la apariencia y que se trataba en realidad de hacer prevalecer la Corona sobre las Cortes. SÁNCHEZ AGESTA, L. (1984).

7 La Constitución recogía una serie de derechos en el capítulo titulado “De los Españoles” bastante parecido al de la Constitución de 1837, aunque más limitada. Se contemplaba la libertad de prensa, de petición, de igualdad legislativa en todo el territorio, acceso a la función pública, reemplazos etc.

8 MARCUELLO BENEDICTO, J.I. (1986).; OLLERO VALLÉS, J.L. (2006). 
escasas competencias, el acceso a los ayuntamientos permanecía cerrado para el conjunto de la población, ya que mediante la Ley electoral del 18 de marzo de 1846 solamente podrían ser electores y elegibles los que contasen con un nivel económico determinado. En este contexto, el alcalde moderado se convirtió en el representante del Gobierno en el municipio, a la vez que gestor de los intereses locales y representante político con inmensas atribuciones.

El oficio de alcalde aparece por primera vez en la Edad Media como ayudante del corregidor y ligado al ejercicio de la justicia. Los textos medievales y de la etapa moderna documentan la existencia de alcaldes de corte en el Consejo de Castilla, alcaldes de rastro ${ }^{9}$, alcaldes de noche para la vigilancia del orden público, etc. El alcalde liberal enlazó precisamente con el alcalde ayudante del corregidor y el alcalde ordinario del Antiguo Régimen de manera que fuese el representante del jefe político en el municipio y fiscalizase al ayuntamiento en su nombre ${ }^{10}$.

Tras la muerte de Fernando VII el Liberalismo decidió crear una administración nueva que abundase en los principios de centralización y jerarquización del poder y así el R.D. del 23 de julio de 1835 atribuía a los corregidores nombrados por el Gobierno y a los alcaldes de los pueblos, ambos bajo la inmediata dependencia de los gobernadores civiles, las competencias sobre la publicación y el cumplimiento de las leyes, las órdenes superiores y los acuerdos de los ayuntamientos; el orden público, la inspección en materia de sanidad y salubridad y la colaboración en materia de propagación de enfermedades o incendios, la concesión de permisos para espectáculos, el registro civil, la presidencia de las sesiones del ayuntamiento y de los actos públicos, la dirección e inspección del personal y servicios del ayuntamiento así como la remisión al gobernador de la documentación referente a los presupuestos, las cuentas del ayuntamiento y cualquier petición de mejora de infraestructuras o de obras públicas. Este decreto fue el primer paso para la unificación de alcaldes y corregidores en una única figura político administrativa para aquellos pueblos estratégicamente importantes, y que los moderados recuperarían para desarrollar tareas esencialmente político administrativas.

En abril de 1840 se presentó un proyecto de ley municipal impulsado por el Ministro Calderón y Collantes que significó un paso adelante en lo que sería el modelo de alcalde moderado y aunque el proyecto fue retirado debido a la oposición feroz por parte de los progresistas, constituyó el germen de lo que sería la Ley de ayuntamientos de $1845^{11}$.

\section{LA ORGANIZACIÓN MUNICIPAL MODERADA}

El 8 enero de 1845 y sin haber realizado una nueva Constitución, se aprueba la Ley de organización y atribuciones de los ayuntamientos del 8 de enero de $1845^{12}$, ley que configuró definitivamente a los ayuntamientos liberales como entidades de base corporativa con un número variable de regidores y tenientes de alcalde, según la población del municipio, ${ }^{13}$ y un único alcalde de base electiva pero que no formaba parte del ayuntamiento, ya que era nombrado por el gobierno y ostentaba la representación ordinaria del mismo en el municipio.

Por encima de los ayuntamientos y del alcalde presidente del mismo estaba el jefe político/gobernador ${ }^{14}$, quien ejercía el control directo de todos los municipios de su provincia a través del nombramiento directo de los alcaldes de los términos municipales con una población inferior a 2.000 habitantes y los alcaldes pedáneos de todos $^{15}$. El jefe político/gobernador contaba con competencias exclusivas en la resolución de conflictos electorales, la suspensión de miembros de las corporaciones o del pleno, la aprobación de los presupuestos municipales con ingresos inferiores a 200.000 reales, el control del alcalde a través de sus atribuciones delegadas, la eliminación de acuerdos tomados por el ayuntamiento en sus sesiones, etc.

9 Ejercían justicia en su distrito o "rastro".

10 El Decreto de las Cortes del 6 de agosto de 1811 sobre la incorporación de los señoríos jurisdiccionales a la nación se caracteriza no solo por dicha supresión, sino también por eliminar a los alcaldes mayores y conservar los ayuntamientos y los alcaldes ordinarios en la administración municipal.

11 Esta ley instauraba el sufragio censitario para la elección de los ayuntamientos y pretendía que alcaldes y tenientes de alcalde fuesen nombrados por el Gobierno.

12 En adelante Ley de ayuntamientos de 1845.

13 En las poblaciones de menos de cincuenta vecinos, se preveían tres regidores y un alcalde. En los que contasen entre cincuenta y uno y doscientos, tendrían un teniente de alcalde y cuatro regidores. Los que estuviesen entre doscientos uno y cuatrocientos contarían con dos tenientes y seis regidores. Los que superasen los cuatrocientos y no superasen seiscientos tendrían dos tenientes y nueve regidores. Los que estuviesen entre seiscientos y mil tendrían dos tenientes y once regidores. A partir de mil y hasta dos mil quinientos tendrían dos tenientes y trece regidores. Desde dos mil quinientos hasta cinco mil contarían con tres tenientes y 16 regidores. A partir de cinco mil hasta diez mil contarían con cuatro tenientes y diecinueve regidores. Desde diez mil y hasta quince mil tendrían cuatro tenientes y veinticinco regidores. De quince mil y hasta veinte mil estarían gobernados por cinco tenientes y veintinueve regidores. En los de superiores a veinte mil gobernarían 6 tenientes y 31 regidores. En el caso de Madrid gobernarían seis tenientes y treinta y siete regidores.

14 El jefe político se convirtió en gobernador mediante el R. D .28 de diciembre de 1849 aglutinando las funciones políticas del jefe político y las hacendísticas del intendente.

15 Ley para el Gobierno de las provincias del 2 de abril de 1845. 
En un peldaño inferior en esta administración jerárquica, pero inmediatamente por encima de los ayuntamientos estaba la diputación provincial, de base corporativa y formada por un diputado representante de cada uno de los partidos judiciales en los que subdividían las provincias, el intendente de rentas y el jefe político/ gobernador como presidente ${ }^{16}$. Las diputaciones fueron creadas por los moderados como meras instituciones deliberantes y al servicio de su presidente y del gobierno ${ }^{17}$.

\section{EL ALCALDE MODERADO: COMPETENCIAS Y LA PRÁCTICA DIARIA}

En esta complicada jerarquía administrativa la figura del alcalde ocupó un lugar fundamental como representante del municipio a la vez que como delegado del Gobierno. Era representante del municipio porque su base era electiva y porque ostentaba la representación local en ceremonias, actos y frente a otras instituciones, pero era delegado del Gobierno porque éste lo nombraba y le otorgaba una serie de competencias por delegación ${ }^{18}$. Como delegado del Gobierno sus poderes se limitaban al pueblo donde ejercía y su inserción en la escala piramidal le impedía comunicarse directamente con el Gobierno o con otras instituciones superiores, de modo que tenía que hacerlo siempre a través del jefe político/gobernador ${ }^{19}$.

\subsection{Funciones delegadas por el Gobierno}

\section{A) Presidencia del Ayuntamiento y comunicaciones con el exterior.}

El alcalde presidía el ayuntamiento en nombre del Gobierno y en ausencia del jefe político/gobernador, lo que le individualizaba como cargo público y le distinguía del resto del consistorio. Entre sus funciones se encontraban ordenar la convocatoria de las sesiones y presidir éstas, pudiendo sustituirle únicamente sus tenientes o un regidor delegado por el mismo, mediante causa justificada y con autorización de la máxima autoridad provincial. Las únicas excusas admisibles eran enfermedad o ciertas cuestiones personales, pero no serán infrecuentes las veces en que el alcalde o los regidores dejen de asistir a las sesiones como fórmula de protesta, o para atender sus propios negocios ${ }^{20}$. La presidencia era una tarea delegada porque el jefe político/gobernador no tenía el don de la ubicuidad, pero éste presidía los plenos en las capitales de provincia donde residía, relegando al alcalde a las tareas de simple regidor. Tanto la presidencia del ayuntamiento como la de los actos públicos se hacía en nombre del Gobierno y nunca del pueblo21.

Entre las tareas del alcalde figuraba también la recepción de las leyes y su comunicación a los regidores durante las sesiones y a la población por medio de bandos ${ }^{22}$. Desde la Real Orden del 22 septiembre de 1836 las leyes fueron de obligatorio cumplimento desde el día siguiente de la publicación en los boletines oficiales. Sin embargo, la falta de tradición en los ayuntamientos sobre la existencia de una normativa obligatoria y común, hizo que fuese necesario obligarlos a suscribirse a la Gaceta de Madrid para que no pudiesen alegar desconocimiento ${ }^{23}$. El alcalde era el encargado de informar al pleno de las novedades legislativas a la vez que debía poner los medios para poner en práctica cualquier cambio legal, bajo amenaza de apertura de expediente y suspensión del cargo ${ }^{24}$.

16 Título XI. “De las diputaciones provinciales y de los ayuntamientos”. Art. 72. En cada provincia habrá una diputación provincial, elegida en la forma que determine la ley y compuesta del número de individuos que ésta señale. Art. 73. Habrá en los pueblos alcaldes y ayuntamientos. Los ayuntamientos serán nombrados por los vecinos a quienes la ley confiera este derecho. Art. 74. La ley determinará la organización y atribuciones de las diputaciones y de los ayuntamientos y la intervención que hayan de tener en ambas corporaciones los delegados del Gobierno.

17 GONZÁLEZ CASANOVA, J. A. (1986).; SANTANA MOLINA, M. (1989).

18 El profesor Germán Rueda define al alcalde como "La figura clave era el alcalde. Era, ante todo, un representante del gobierno por línea jerárquica desde la Corona a través de los jefes políticos o gobernadores. El gobierno podía reforzar su poder nombrando un alcalde corregidor para sustituir al ordinario". RUEDA HERNANZ, G. (2006).

19 MORELL OCAÑA, L. (1977).; CAJAL VALERO, A. (1999).

20 PÉREZ RODRÍGUEZ. A. C. (2012). La tesis demuestra que las renuncias a ocupar los cargos públicos y la negativa a participar en las elecciones, así como otros actos de rebeldía por parte de los notables locales serán una constante en la política del Ayuntamiento de Santiago de Compostela entre 1845 y 1868.

21 Las actas municipales del ayuntamiento de Santiago de Compostela así como la prensa de la ciudad, muestran al alcalde presidiendo la ofrenda al Apóstol, en sustitución de la Reina, el Gobierno o el jefe político, a la vez que presidía rogativas públicas, el teatro, las fiestas, las entregas de premios, las subastas públicas, etc. en nombre de un gobierno lejano pero siempre presente.

22 Era obligatorio tener el Boletín en la secretaría del Ayuntamiento para su consulta por los vecinos y autoridades municipales. La suscripción al Boletín Oficial de la Provincia ya venía siendo obligatoria desde mediados de los años treinta, y se obligaba a los alcaldes a reclamar al editor cualquier número que faltase

23 El editor tenía la obligación de publicar todo lo concerniente a los pueblos y los acuerdos de los ayuntamientos, previamente revisados por el jefe político. R.O. del 20 de abril de 1833 y R.O. del 6 de abril de 1839.

24 Un ejemplo claro de ello lo encontramos en la Real Orden del 15 de julio de 1851, Gaceta de Madrid del 19 de julio de 1851 , por la cual se le deniega la petición de autorización del juez de primera instancia de Santiago de Compostela para procesar a Narciso Zepedano, AlcaldeCorregidor de la ciudad. El juez había solicitado procesarlo alegando que Zepedano había destituido al secretario contador del Gran Hospital de Santiago y nombrado a otra persona para el cargo, usurpando así las competencias del juzgado y realizando apremios ilegítimos. El Gobierno denegó tal permiso de procesamiento porque el corregidor cumplía órdenes suyas y cita para ello la Ley del 2 de abril de 1845 (Art. 7) por la cual los jefes políticos tenían la obligación de comunicar a los alcaldes sus órdenes y éstos de cumplirlas. 
La suscripción a los boletines constituía en sí mismo un instrumento de uniformidad legislativa y de control de las actuaciones locales, pero los alcaldes utilizaron a menudo también estos mecanismos para hacer valer sus competencias y reclamar la actuación del Gobierno en asuntos de interés local25.

La legislación constituía un gran problema para los ayuntamientos, no solo porque el Gobierno pocas veces tenía en cuenta la situación en que se hallaban las administraciones locales para legislar sobre ellas, sino porque además, en la resolución de conflictos tenían más peso los intereses particulares que los generales del municipio. Un buen ejemplo de los contratiempos que causaban los continuos cambios legislativos lo constituye el caso de Ignacio Alcalde, un arrendatario de Santiago de Compostela que remató el impuesto de arbitrios y consumos en 1852 y que al poco tiempo de hacerlo, decidió renunciar al arriendo porque un cambio legislativo gubernamental en materia impositiva le ocasionaba pérdidas económicas ${ }^{26}$. El ayuntamiento resultó muy perjudicado por el abandono del arriendo, ya que no solo no pudo hacer frente a los gastos presupuestados, sino que pasó adeudar una gran cantidad a la hacienda estatal en concepto de consumos. Estos hechos provocaron un largo pleito entre la corporación y el arrendatario, un litigio que perdió el municipio, al contar el arrendatario con buenos contactos en los gobiernos de la Unión Liberal27.

El alcalde, además de comunicar, podía reclamar en nombre del ayuntamiento en casos de abuso por parte de particulares o autoridades superiores y podía solicitar permisos especiales de ejecución para determinados asuntos que no figuraban entre sus potestades. Ambos casos exigían una vía protocolaria muy estricta denominada exposición de motivos ${ }^{28}$. El protocolo incluía tres pasos fundamentales ${ }^{29}$ : encargar su redacción a una comisión especial cuyo trabajo sería leído, votado y aprobado mayoritariamente por el ayuntamiento, cuidar que la redacción estuviese dentro de los cánones de respetuosidad fijados por el Gobierno y enviar la exposición al jefe político/gobernador para que la hiciese llegar al destinatario.

\section{B) La organización y celebración de elecciones}

El alcalde se encargaba de garantizar la celebración de las elecciones y unos resultados acordes con los deseos del partido gobernante. En el tema electoral estaba sometido a la "influencia moral" del Gobierno, cuyo fenómeno al igual que el "cunerismo", afectaba sobre todo a las elecciones provinciales y a las de Cortes, pero que también se daba en las municipales ${ }^{30}$. El alcalde se encargaba junto a dos concejales y dos mayores contribuyentes elegidos por sorteo, de elaborar las listas electorales para las elecciones municipales y de realizar los informes personales para las listas de diputados a Cortes. Además, se le otorgó la presidencia de la mesa electoral y la resolución de reclamaciones sobre el proceso electoral, de modo que cualquier recurso sobre su gestión tenía que serle presentado para que lo informase y lo elevase al jefe político/gobernador.

\section{C) El mantenimiento del orden público y la moralidad pública}

Los liberales en general y los moderados en particular pusieron especial énfasis en cuidar del mantenimiento del orden y seguridad pública. La exposición que antecede al Real Decreto del 25 de enero de 1844 establecía como objetivo principal de cualquier gobierno el velar por los intereses de los contribuyentes, protegiendo no sólo a las personas físicas sino también a los negocios y propiedades. Las tareas del alcalde en este ámbito se referían fundamentalmente al conocimiento de la legislación vigente y la remisión inmediata de cualquier problema que pudiera surgir a sus superiores en la provincia. Además, en casos de delitos, remitía al juez de primera instancia un expediente de primeras actuaciones e inmediatamente quedaba relevado de cualquier responsabilidad, a no ser que se tratase de pueblos en los que no hubiese ni Guardia Civil ni juez de primera instancia, caso en el que sustituía a estas autoridades para realizar las primeras actuaciones de persecución, apresamiento y memoria de acusación.

25 El conocimiento legal podía evitarle al alcalde el ser castigado ya que el Gobierno no admitía el desconocimiento. La ley de 20 de abril de 1833, título I, partida 7 dice "la ignorancia de las leyes no excusa la pena". Esta máxima se siguió manteniendo todo el período moderado como forma de control de las corporaciones por parte del gobierno.

26 IGLESIAS OTERO, M.L Y PÉREZ RODRÍGUEZ, A.C. (2001).

27 Las pérdidas derivadas de este pleito y la presión de la administración central sobre la población, hicieron que en adelante el consistorio siempre se adelantase a cualquier eventualidad y pidiese garantías para los arriendos tratando de contrarrestar una legislación cambiante y poco madura.

28 Se exceptúan de esta regla general las exposiciones que hagan los alcaldes en solicitud de rebajas de contribuciones, pues esta clase de instancias se dirigirán por conducto de los intendentes y no por los jefes políticos. R.D. de contribuciones 23 mayo de 1845 , Art. $48-54$.

29 R.O. de 12 de mayo de 1840. Si el envío de la exposición no sigue este protocolo no solo dejará de ser cursada, sino que además se tomarán las medidas para castigar al ayuntamiento que no lo haga. Ver también R.O. de 9 de enero de 1837.

30 CABALLERO, M. (1994).; FORNER MUÑOZ, S. y GARCÍA ANDREU, M. (1990). 
El alcalde era el jefe inmediato del personal municipal encargado del mantenimiento del orden público y actuaba como coordinador en la realización de padrones de vecindario, la expedición de visados y pasaportes ${ }^{31}$, así como en la inspección de posadas, cafés y demás establecimientos públicos de ocio y venta. Además, la legislación preveía que realizasen rondas nocturnas con los miembros del consistorio y el personal municipal para garantizar cuestiones como la utilización de una correcta vestimenta durante la noche ${ }^{32}$, la seguridad en las calles y caminos o la adecuada iluminación de casas y calles ${ }^{33}$.

Formando parte de las tareas de orden público, ocupaba un espacio muy importante la recopilación de información sobre el número de pobres del municipio y sus condiciones de vida. Se trataba de evitar las revueltas sociales provocadas por el desabastecimiento o las crisis económicas puntuales que se repetían periódicamente causando numerosos desórdenes públicos y avocando a una gran parte de la población a la emigración ${ }^{34}$. En realidad ni el alcalde ni los ayuntamientos contaban con medios eficaces con los que hacer frente a la pobreza o a la extensión de enfermedades, ya que no solo faltaban medios económicos, sino también técnicos y de capacidad de gestión. Los gestores municipales carecían de formación específica en cuestiones de economía, gestión pública e incluso política y además todas sus actuaciones tenían que pasar el filtro del jefe político/gobernador con lo cual la respuesta a cualquier problema era lenta y dificultosa. Un ejemplo de ello lo tenemos en el motín de subsistencias acaecido entre el 17 y el 20 de marzo de 1847 en Santiago de Compostela cuando una gran multitud de mujeres apedrearon la casa del comerciante y regidor Andrés María Fariña y le acusaron de enviar el grano al exterior a través del puerto de Carril y desabastecer la ciudad desde el 26 de febrero de $1847^{35}$. Ante la magnitud del motín, el ayuntamiento decretó la prohibición de exportar grano, pero no pudo pagar los precios del almacenado en los graneros, ni recuperar el ya enviado. A los pocos días tuvo lugar la remoción del gobernador y unos meses más tarde se dio a conocer a los regidores que debían continuar en el cargo, produciéndose numerosas protestas entre éstos porque no querían renovar ${ }^{36}$.

Dentro de las tareas de orden público figuraba también la protección de las instituciones del Estado. El alcalde actuaba con la capacidad que le otorgaba el figurar como representante del Ministerio de Gobernación en delitos contra la Monarquía, el Gobierno, la Constitución o la Iglesia. Eran considerados delitos contra la Monarquía los que podían tener consecuencias físicas para cualquier miembro de la familia real (muerte, secuestro o alteración de la sucesión) y también los que pudieran contribuir a minar el prestigio de la institución o modificar sus prerrogativas y autoridad. Se consideraban agresiones contra el Gobierno y la Constitución aquellas que tratasen de desestabilizarlos, así como modificar o dejar de cumplir las obligaciones determinadas en la Carta Constitucional. También se consideraba delito las actuaciones encaminadas a impedir el normal funcionamiento del Estado, como el impedimento de las elecciones, la coacción a los electores, la falta de obediencia a las leyes estatales, etc. En la esfera religiosa se calificaba de delito las actuaciones que impidiesen la celebración de los actos religiosos, tanto dentro como desde fuera de los templos, las procesiones o los actos de representación, así como los que se profesasen contra los sacerdotes y demás personal religioso ${ }^{37}$.

El alcalde tenía que identificar estos delitos considerados en su mayoría como traición o conspiración y comunicarlos inmediatamente al jefe político/gobernador. En su labor, fiscalizaba las consignas emanadas de los discursos públicos, los gritos y proclamas proferidos en los motines, las conversaciones de reuniones, fiestas y

31 Bando del 1 de octubre de 1849 comunicando la supresión de los gobiernos civiles por Real Orden y encomendando a los alcaldes corregidores los ramos de protección y seguridad pública. Se establece que pasaportes y demás documentos de policía estén disponibles en las casas consistoriales en horario de ocho de la mañana a dos de la tarde y de cuatro a ocho, y con las siguientes normas: no se le expedirá pasaporte o pase sino va acompañada la solicitud de la papeleta de abono del respectivo alcalde de barrio, excepto los forasteros que tengan pasaporte y les concluya en esta ciudad. Los dueños de fondas, cafés, pastelerías, ultramarinos, tabernas, etc., que tengan la obligación de tener una licencia de protección y seguridad pública para el ejercicio de su profesión, se presentarán en tres días para renovar su licencia u obtenerla por primera vez.

32 Recordemos que los sacerdotes, los militares, y otros colectivos, estaban obligados a vestir con sus ropas especiales y que una dama jamás podía ir vestida de caballero y viceversa.

33 Debido a la enorme cantidad de robos, se creó un cuerpo específico de ronda denominado "Ronda de Policía Urbana" que vigilaría la población cuando no lo hiciesen los serenos, es decir durante el día. Ver bando de policía urbana de Santiago de Compostela del 22 de febrero de 1848, dado por el Alcalde-Corregidor Miguel Díaz.

34 CARASA SOTO, P. (1991); MAZA ZORRILLA, E. (1999).

35 La población se encontraba enardecida por la falta de granos y los excesivos precios de éstos, pero sobre todo estaba muy preocupada por los rumores que existían sobre la concentración de granos en el Puerto de Carril para llevarlos fuera de Galicia. El ayuntamiento se preocupó realmente por la magnitud del motín y comunicó al gobierno que a pesar de que no encontraba pruebas de que existiese tras el motín un movimiento o un partido político, era muy probable que las masas fuesen presa fácil de quien desease llevar a cabo una revolución.

36 AHUS, Fondo municipal, Actas Consistoriales, sesión del 30 de julio de 1847.

37 Reglamento de Policía Urbana de Santiago de Compostela de 1850. El alcalde contaba entre sus atribuciones el asegurarse de que los eclesiásticos residiesen en sus iglesias y que si saliesen del pueblo contasen con la autorización del Prelado. Se encargaba también de evitar abusos en las exacciones de derechos, de no autorizarles la apertura de negocios y que siempre vistiesen los hábitos de su profesión y que no saliesen después del toque de queda. 
demás actos donde se reuniesen varios ciudadanos, los impresos anónimos, los libros y demás impresiones con autor, los foros y ateneos, etc., es decir el alcalde estaba al tanto de todo lo que ocurría en su territorio en nombre de la salvaguarda de las instituciones del Estado.

El presidente de la corporación contaba con facultades para detener o multar a todo aquel que fuese sorprendido en la perpetración de delitos como realizar juegos prohibidos por la ley ${ }^{38}$, vestir incorrectamente, emborracharse en la calle, ejercer la prostitución, organizar fiestas o bailes sin observar las reglas de policía urbana39, estar amancebado, usar del suelo sagrado para realizar fiestas o juegos no relacionados con la religión, blasfemar o utilizar palabras malsonantes, portar armas ${ }^{40}$, abrir las tiendas y negocios los días festivos ${ }^{41}$, etc.

Las competencias del alcalde se manifestaban de modo especial en la vigilancia de los espectáculos públicos como el teatro, donde revisaba los contenidos de las obras tras el trabajo del censor y presidía los estrenos. Hasta 1849, los alcaldes obligaban a los contratistas de espectáculos a “donar" una parte de las ganancias a la comisión de beneficencia para el pago de las facturas que generaba la pobreza ${ }^{42}$. Estas facultades fueron anuladas por el Gobierno en 1849, al igual que los derechos a tener reservadas localidades de honor y presidir las funciones y se le otorgaron al gobernador o quien éste designase. En adelante, los ayuntamientos no tendrán más intervención en los teatros que el arrendamiento de los edificios, siempre que le perteneciesen en propiedad ${ }^{43}$, y el derecho a legislar sobre el comportamiento en los mismos, de modo que serán abundantes los bandos de policía urbana sobre la necesidad de observar las reglas de la moralidad pública en estos lugares y no usarlos "como si fuesen tabernas" 44 .

\section{D) La salud pública}

El ayuntamiento era el responsable de la organización y mantenimiento económico de la salud pública, pero no contaba con facultades legislativas ni ejecutivas que le permitiesen adoptar medidas de urgencia ${ }^{45}$. El alcalde inspeccionaba con otros miembros del ayuntamiento los locales públicos a la vez que fiscalizaba la higiene de los abastecimientos, pero no podía hacer frente a la extensión de enfermedades epidémicas ya que sus atribuciones se limitaban a informar a la población y esperar a que el jefe político/gobernador actuase. Además de los inconvenientes citados, los ayuntamientos permanecían sistemáticamente al límite del endeudamiento, de modo que era imposible dotar partidas anuales suficientes para abordar imprevistos.

Entre las atribuciones del alcalde en materia de salud pública estaba la limpieza de calles y fachadas ${ }^{46}$, la correcta canalización de las aguas insalubres, la limpieza de jardines y huertas o el control de potabilidad de las aguas. En estas tareas el alcalde actuaba como coordinador de los veedores municipales garantizando el cumplimiento

38 Bando del Ayuntamiento de Santiago del 28 de mayo de 1846. Se prohíben las batallas de piedras entre los jóvenes.

39 Bando del Ayuntamiento de Santiago del 19 febrero de 1849. Se hace saber que el producto de los bailes de carnaval se concede exclusivamente a la casa hospicio y a la Sociedad Económica de Amigos del País. Las normas eran: se prohíben los bailes particulares de máscaras los días en que haya bailes públicos en la Casa Teatro, bajo multa de 20 ducados al dueño de la casa. Se permite ir disfrazado y con careta hasta el anochecer en los tres días de carnaval quedando prohibido los demás días bajo multa de 4 ducados. Se prohíbe el uso de vestimentas de disfraz sobre ministros de la religión, funcionarios públicos, militares o insignias del estado. Se prohíbe también llevar armas, insultar, quitar a los demás la careta, etc.

40 Bando del 24 de febrero de 1848 haciendo públicas las reglas a observar los días de carnaval. Se prohíbe a todas las personas que acudan a los bailes con armas, palos u objetos que puedan causar daños, exceptuando las autoridades civiles y militares, así como arrojar cualquier objeto a los viandantes y público.

41 Bando del 25 de agosto de 1848 prohibiendo de acuerdo a la Novísima Recopilación Leyes 7 y 8 titulo 1, libro 1, que las tiendas de comercio sean de la clase que sean, a excepción de comestibles o bebidas, estén abiertas los días festivos. Los tenientes de alcalde, regidores y alcaldes de barrio y celadores de calle cuidarán en sus distritos barrios y calles que se cumpla esta orden y serán los guardias municipales, alguaciles y serenos y los tenientes de alcalde los que efectúen las denuncias.

42 R. O. 26 diciembre de 1833. Aunque las leyes prohibían los bailes de máscaras, los reglamentos de policía urbana los permitían si eran autorizadas por el jefe político y además se hacían con fines benéficos y bajo reglas estrictas.

43 Art. 26, 28 y 29, Real Decreto del 7 de febrero de 1849, Gaceta de Madrid del 8 de febrero de 1849, №. 5262 . Se establecía que en adelante los ayuntamientos se limitasen a concertar el arriendo de los locales del teatro si eran de su propiedad y que en los contratos estipulasen únicamente el tiempo de arriendo, el precio. Se les encargaba también la conservación de los edificios y enseres pero no se les permitía exigir arbitrios distintos a los estipulados en los presupuestos de ingresos ni obtener beneficios por la reserva de lugares.

44 Bando del Ayuntamiento de Santiago del 13 de julio de 1854 sobre la forma de comportarse en el teatro. Se prohíbe fumar a no ser en los corredores y salón de descanso, también se prohíben los silbidos, gritos, palabras obscenas, etc., entablar conversaciones de un punto a otro del teatro, dirigir palabras a los actores y en definitiva, se prohíbe cualquier acción indecorosa y que se altere el orden. Bando del 6 de mayo de 1858 sobre el mismo tema y las mismas normas.

45 Gaceta de Madrid del 21 de mayo de $1853, \mathrm{n}^{\circ} 141$.

46 Bando del Ayuntamiento de Santiago de Compostela del 7 agosto de 1858 dictando normas de policía urbana. Se manda que $\mathrm{n}$ ocho días queden libres de escombros y materiales todas las calles y plazas de la ciudad bajo multa de 300 reales para los dueños de las obras donde procedan. Se obliga a que se blanqueen las fachadas, paredes, laterales de las casas que den a calles y callejones. También se lavarán las fachadas de sillería de cafés, tiendas de comestibles etc. Se prohíbe secar ropas en los balcones y ventanas o tejados que den a la calle. Se prohíbe bajo multa de 100 reales arrojar a la calle por puertas o ventanas aguas e inmundicias, a cualquier hora del día o de la noche. Se prohíbe colocar en las calles o aceras y parte exterior de los talleres de carpintería, ebanistería etc. muebles, maderas, etc. que ofendan el aspecto público e interrumpan el paso de los transeúntes. 
de las normas gracias a su capacidad de establecer multas. Además, vigilaban que los comerciantes traficasen únicamente con lo estipulado para su empresa y que sus materiales se encontrasen en perfectas condiciones en los almacenes y en los puntos de venta.

Las autoridades eran especialmente cuidadosas con las mercancías peligrosas como las de los $\operatorname{coheteros}^{47}$ o las empresas madereras y obligaron en general a situar las fábricas fuera de los pueblos ${ }^{48}$. En este sentido, ayuntamientos como el de Santiago de Compostela trabajaron durante años en proyectos como los de instalación de todas las fábricas peligrosas en las afueras de la ciudad y en la creación de un cuerpo de bomberos que permitiese acometer los numerosos incendios que se declaraban debido a unas estructuras arquitectónicas deficientes y la falta de precauciones en la manipulación de las mercancías.

\section{E) La promoción económica de los pueblos y la lucha contra el fraude fiscal}

Los alcaldes invertían mucho de su tiempo en promocionar la economía local a través de la difusión de información sobre innovaciones tecnológicas, exposiciones, ferias, premios de desarrollo de nuevas técnicas o productos, etc. El objetivo era el fomento de la competitividad y la inversión y por ello también se le facultaba para otorgar patentes y certificados de autenticidad sobre un producto o artilugio de fabricación local ${ }^{49}$.

La conservación del patrimonio artístico público y la rentabilidad del mismo constituían un objetivo importante para los ayuntamientos y para sus presidentes. En este sentido, los alcaldes ordenaban la realización de estudios sobre el estado de edificios, esculturas, libros, pinturas y demás obras artísticas incluidas en el patrimonio municipal y dedicaban una partida anual para su conservación, así como también para la adquisición de nuevas obras y la difusión de la cultura, tanto en el pueblo como en el exterior. Esta tarea se vio sumamente afectada por la falta de claridad sobre la propiedad de los edificios desamortizados y de las obras de arte, hecho que fue aprovechado por los ayuntamientos para evitar sufragar sus gastos. En el caso de los cuarteles e inmuebles estatales, los ayuntamientos hubieron de asumir sus gastos de mantenimiento y reparación, aunque la propiedad continuase en manos del Estado.

En general los alcaldes contaban con atribuciones para promocionar las actividades económicas de las poblaciones que gobernaban, pero su utilización iba a depender de su formación e intereses. Así, en Santiago de Compostela los alcaldes optaron por promocionar el comercio o la industria mayorista, a la vez que ponían trabas a los puestos ambulantes alegando que afeaban calles y plazas y favorecían la evasión de impuestos. Un ejemplo de ello lo tenemos en la retirada de los "ropavejeros" al Torreón de San Agustín, debido a que el entonces alcalde, Ignacio Araujo, consideraba:

"vergonzosos ver colgados en las plazas y calles principales los andrajos miserables y sucios e intolerables, los perjuicios que causan embarazar el tránsito con muebles y trastos viejos..."

Lo mismo ocurrió con las panaderas de la plaza del pan y otros mercaderes del regateo, que a pesar de contribuir a potenciar la actividad económica de la ciudad, resultaban molestos al ayuntamiento porque era muy difícil obligarlos a pagar impuestos y resultaba muy complicado controlar la calidad de sus mercancías. La necesidad de fiscalizar el comercio provocó también que se obligase a los vendedores a ubicarse en plazas de abastos o lugares públicos especificados para ello, prohibiéndoles colocar las mercancías en las puertas de entrada a la ciudad $^{51}$. El objetivo era la recaudación de arbitrios y consumos de manera sencilla y rápida, pero también evitar el desabastecimiento de los mercados y la consecuente subida de precios ${ }^{52}$.

47 Bando del Ayuntamiento de Santiago de Compostela del 3 de septiembre de 1845 haciendo saber a los coheteros y fabricantes de combustible que sino trasladan sus talleres a las afueras de la población, casetas de Andujar, como mandaba el bando del ayuntamiento de 21 de noviembre de 1843 incurrirán en multa de 50 ducados. Los alguaciles que no den parte de esto se les descontará un mes de sueldo.

48 El Ayuntamiento de Santiago ordenó reiteradas veces la retirada de los talleres a las afueras de la ciudad pero debido a la gran influencia económica de los coheteros en el ayuntamiento las presiones pierden fuerza y los talleres no son retirados.

49 Era obligatorio que cada producto fabricado en el pueblo y que fuera presentado en un concurso, llevase los sellos del alcalde del pueblo y un informe del jefe político detallando la composición y la utilidad del mismo.

50 Bando de policía urbana del 3 de diciembre de 1845. En adelante nadie podrá dedicarse a este tráfico sin prestar fianza al celador de su cuartel y al comisario de protección y seguridad pública. No se le permitirá colocarse en ningún punto fuera del señalado bajo multad e dos ducados en primera vez y cuatro la segunda, etc.

51 Bando de policía urbana del Ayuntamiento de Santiago de Compostela del 1 de septiembre de 1854.

52 Bando del Ayuntamiento de Santiago de Compostela 14 de junio de 1845 haciendo saber que se prohíbe que salgan a comprar a los caminos a las regateras o traficantes de fruta, aves y toda clase de caza que se dirija al pueblo para ser vendida en la plaza hasta después de las diez de la mañana para que puedan comprar antes los particulares. Los infractores de esta disposición perderán la mercancía comprada y la mitad del valor será para el aprehensor y la otra mitad para la casa hospicio. Serán los celadores de protección y seguridad pública y los dependientes auxiliares de los pueblos los encargados de que se cumpla la medida y que presten a los serenos y sus capataces los auxilios necesarios. Se vuelve a prohibir por bando de 31 julio de 1847 y sucesivos. Las mercancías apresadas se repartirían al $50 \%$ para los pobres y para los funcionarios aprehensores. 
Además de fomentar la riqueza de los pueblos, los alcaldes debían garantizar el abasto de los mismos a precios razonables. Para ello estaban obligados a contar con una plaza de abastos dotada de unidades de pesos y medidas regladas, así como un código de comercio a disposición de los compradores. El alcalde, a través del fiel manferidor, los fieles contrastes y los fieles de puertas, debía asegurarse de que no se cometiese fraude contra los consumidores, ni en los pesos y medidas, ni tampoco en las monedas que se utilizaban para los intercambios ${ }^{53}$. Estos trabajadores emitían informes mensuales sobre la legalidad del comercio y de todos los instrumentos utilizados habitualmente en el tráfico comercial: monedas, pesos y medidas, salubridad de los puestos y autorización municipal para el negocio. El alcalde contaba con datos fiables sobre la evolución anual de los precios, ya que un comisionado escribano recogía mensualmente datos en el mercado y daba a conocer las estadísticas en el mes de julio de cada año54.

El alcalde empleaba también muchos de sus recursos en la celebración de ferias y mercados, abastecer estos lugares de todo tipo de mercancías, así como en dar a conocer los productos locales. Esta facultad le otorgaba mucho poder entre los comerciantes y al mismo tiempo, le convertía en árbitro de los intereses de los distintos grupos económicos de los pueblos. Los ayuntamientos conocían como nadie el funcionamiento de los mercados, principales centros de abastecimiento de los pueblos, y en los momentos de crisis económica trabajaban en iniciativas destinadas a paliar la escasez de alimentos en los mercados, o frenar el ascenso o caída de los precios ${ }^{55}$. Así, las competencias municipales en materia de precios se fueron ampliando debido a la necesidad de respuesta que ocasionaron las hambrunas de 1852/53 por la pérdida de cosechas y la consiguiente bajada demográfica a causa de las fiebres tifoideas en verano y el cólera en el invierno de $1853^{56}$. Desde este momento fueron frecuentes las órdenes del gobernador para que los alcaldes elaborasen informes sobre el aumento de la pobreza, deteniéndose en el estado de las condiciones de la localidad, los precios de los artículos de primera necesidad, los salarios, los jornales de los obreros y demás datos que pudiesen estimar convenientes y propusiesen además, iniciativas para paliar estos problemas ${ }^{57}$.

Por último, el alcalde debía impedir el contrabando y la evasión de impuestos ${ }^{58}$. Una de sus competencias en este tema consistía en recibir las denuncias, formalizar un expediente de acusación, firmarlo y enviarlo al juez competente 59 . Además, colaboraba con las partidas de resguardo encargadas de perseguir el contrabando y acompañaba a los empleados de seguridad pública cuando tenían que entrar en un domicilio o propiedad y el dueño se oponía ${ }^{60}$.

\section{F) Las funciones judiciales y los medios de sanción}

El alcalde del Antiguo Régimen era un oficio esencialmente jurídico a la que en ocasiones se le añadían otras funciones ${ }^{61}$. En ese momento, no existía la división de poderes y su atribución principal era la administración de justicia por orden del Rey y para ello llevaba la "vara de justicia"62. Con el paso del Antiguo Régimen al Liberalismo se construye un tipo distinto de alcalde al que se aplican los principios de soberanía nacional y división de poderes y

53 FERNÁNDEZ CASANOVA, M.C. (2011).

54 Este escribano era siempre el mismo y cobraba por este trabajo del ayuntamiento de Santiago de Compostela 133 reales. Las actas del Ayuntamiento de Santiago de Compostela reflejan en el mes de julio desde 1844 a 1868 la misma cantidad.

55 Un ejemplo de estas iniciativas la encontramos en la sesión del Ayuntamiento de Santiago de Compostela del 11 de mayo de 1857 , donde el alcalde llamó la atención sobre el excesivo precio que estaba teniendo la carne en el mercado y propuso obligar a los comerciantes a rebajarlo mediante el establecimiento de un banco fiscal regentado por el ayuntamiento donde se vendiese más barato. AHUS, Fondo municipal, Actas Consistoriales, Sesión 11 de mayo de 1857.

56 Gaceta de Madrid del 25 de mayo de 1853, $n^{\circ} 145$, habla de la pérdida de las cosechas y la Gaceta de Madrid del 21 de mayo de $1853 \mathrm{n}^{\circ}$ 141, atestigua la aparición del cólera en Noya y la necesidad de tomar medidas.

57 AHUS, Fondo municipal, Actas Consistoriales, sesión 14 de marzo de 1862.

58 IGLESIAS OTERO, M. L.; PÉREZ ROdRíGuEZ, A. C. “Consideraciones generales..., 2001. Pág. 93-108.

59 Hay que tener en cuenta que se alentaba la denuncia de esta infracción por todo vecino que tuviese conocimiento de ello, reservándole una recompensa y la absoluta confidencialidad de datos a los que presentasen denuncias contra personas que presuntamente ejerciesen contrabando. Art. 100 Ley Penal de 3 de mayo de 1830.

60 Orden del 19 de diciembre de 1842, Resolución de 10 de mayo de 1842 y R.O. 30 enero de 1844. Se amenazaba a los ayuntamientos con consecuencias graves sino colaboraban con las autoridades competentes para perseguir el contrabando.

61 MORILLO-VELARDE, (1997). Pág. 11.

62 CEBREIROS ÁlVAREZ, E. (1999). Pág. 86. 
se convierte en una figura esencialmente gubernativa con ciertas prerrogativas judiciales ${ }^{63}$. La Ley del 3 de febrero de 1823 y el Real Decreto del 26 de septiembre de 1835 continúan en esta misma dirección, consagrándolo como magistratura de tipo político administrativo con ciertos residuos judiciales (conciliadoras, contenciosas civiles y contencioso-criminales de mínima cuantía ${ }^{64}$. Estos residuos continuarán hasta 1855 y son muchos los autores que consideran que se mantuvieron porque resultaba más barato para el Estado utilizar a los alcaldes para casos de escaso calado, que dotar a los partidos judiciales de funcionarios específicos de justicia ${ }^{65}$.

Las facultades judiciales de los alcaldes provocaron numerosos conflictos de competencias con los jueces de partido por la insuficiente delimitación de funciones y atribuciones. Como ejemplo de estos conflictos de atribuciones podemos mencionar la sustitución del Contador del Gran Hospital de Santiago de Compostela por otra persona de la confianza del Gobierno. En principio el contador Ángel Patiño, no ofrece resistencia al cese, pero se niega a abandonar la casa que ocupaba dentro del Hospital y que venía siendo parte de su salario. El alcalde trató de resolver la cuestión emitiendo varios apremios pero el contador lo denunció al Juez del Partido por usurpación de funciones del Juzgado y emisión de apremios ilegítimos y sin autorización. El Juez del Partido admitió la causa y pidió permiso al Consejo Real para procesar al alcalde, lo que le fue denegado por el Gobierno ya que el alcalde actuaba en su nombre y estaba autorizado a utilizar cualesquier medios necesarios ${ }^{66}$. Otro ejemplo es el intento del Juez de Primera Instancia de Santiago de Compostela de procesar a Manuel Turnes, Teniente Alcalde de Santiago y al Alcalde de Arzúa, Manuel González, acusándoles de detención arbitraria y usurpación de funciones del juzgado ${ }^{67}$, debido a que ambos se negaban a reconocer la condición de vecino a un preso para evitar pagar su mantenimiento ${ }^{68}$.

Estos conflictos de competencias eran muy frecuentes y aunque causaban muchos perjuicios a las administraciones locales, beneficiaban a los gobiernos de turno porque les permitía actuar de árbitros en los conflictos en beneficio de las instituciones que deseaban reforzar ${ }^{69}$.

Los alcaldes contaban con funciones judiciales en los juicios de conciliación, donde actuaban como mediadores entre las partes para evitar pleitos y la saturación de los tribunales. Los juicios de conciliación eran obligatorios como paso previo a cualquier demanda, pero en casos de obras, herencias o inventarios, se podía prescindir de ellos y entablar la demanda directamente. En el resto de los casos, el alcalde con asistencia del escribano, oía a las partes y a los testigos, emitía un informe para conciliarlos y asentaba los resultados en los libros de "juicios de paz". Se levantaba acta con la firma de todos los que habían participado en el juicio y se dejaba constancia de si las partes se habían conformado con el veredicto o no ${ }^{70}$.

Los alcaldes actuaban también en los juicios verbales por pleitos civiles, siempre que no existiese juzgado de primera instancia y que se litigase por un valor inferior a 200 reales, siendo los restantes casos de la competencia

63 Constitución de 1812, Título V. “De los tribunales y de la Administración de Justicia en lo civil y en lo criminal” Capítulo I. “De los tribunales" Art. 275 "En todos los pueblos se establecerán alcaldes y las leyes determinarán la extensión de sus facultades, así en lo contencioso como en lo económico". Art. 282. "El alcalde de cada pueblo ejercerá en el oficio de conciliador y el que tenga que demandar por negocios civiles o por injurias, deberá presentarse a él con este objeto". El Reglamento de Audiencias y Juzgados por Decreto de Cortes del 9 de octubre de 1912, Capítulo III regulaba la actuación de los alcaldes como jueces ordinarios en materia civil y penal. En materia civil conocerán en sus pueblos, además de la conciliación de las demandas que no pasen de quinientos reales. de vellón en la península o islas adyacentes y de cien pesos fuertes en ultramar y de los negocios criminales que no merezcan otra pena que alguna represión o corrección ligera. También conocerán en todo tipo de diligencias civiles hasta que llegaran a ser contenciosos entre partes, en cuyo caso lo remitirán al juez de partido. En materia penal proceden de oficio para formar las primeras diligencias del sumario y prender a los reos, dando cuenta inmediata al juez de partido. Los jueces deben usar siempre de los alcaldes para operar diligencias en los pueblos por causa civil y criminal y nunca de otra magistratura.

64 Para profundizar en la administración municipal y la figura del alcalde creada por el Liberalismo consultar el artículo PÉREZ RODRÍGUEZ, A. C. (2014). Pág. 60-64.

65 Oliván afirmaba: "Si en cada localidad pagase la administración general un empleado o agente resultaría un gasto exorbitante y sería difícil conservar la buena diligencia entre él y el mandatario y magistrado del pueblo (...) por donde se turbaría la armonía social cuando uno y otro servicio deben conciliarse apoyándose mutuamente" OLIVÁN Y BORRUEL, A. (1843). Pág 104.

66 Art. 7 de la Ley del 2 de abril de 1845 que establece que los subdelegados de los jefes políticos están obligados a obedecer y cumplir las disposiciones del Gobierno sin que por obediencia puedan incurrir en responsabilidad de ninguna clase.

67 Gaceta de Madrid del 19 de junio de 1862, № 170.

68 El detenido, Marcos Punin, fue apresado por el comandante de la guardia civil por estar reputado como vago, no tener cédula para viajar y ser sospechoso de haber sido procesado y fue puesto bajo custodia del alcalde de Arzúa, quien lo mandó a Santiago alegando que era vecino de la ciudad. El teniente de alcalde de Santiago tras dos semanas de averiguaciones lo hizo regresar a Arzua diciendo que era vecino de aquel municipio, pero el alcalde no lo quiso allí y lo obligó a regresar a Santiago donde el alcalde de esta ciudad no pudo procesarlo por falta de competencias. El detenido denunció al juez de primera instancia la conducta de ambos alcaldes pero el juez tampoco pudo hacer nada porque el gobernador suspendió la causa diciendo que habían actuado bajo el Art. 73 de la Ley de ayuntamientos de 1845.

69 El Consejo Real dicta sentencia en la Real Orden del 15 de julio de 1851 y aparece publicada en la Gaceta de Madrid del 19 de julio de $1851, N^{\circ} 6214$.

70 El Real decreto de 12 de julio de 1847 mandaba que los alcaldes y tenientes de alcalde que tomasen parte en los juicios llevasen dos libros diferenciados: “juicios verbales” y “juicios de conciliación” y que lo hiciesen por duplicado para poder entregar un ejemplar en el juzgado de paz. 
del juez de primera instancia. En estos juicios, el alcalde dependía directamente de la audiencia del distrito y del juez del partido e informaba a las autoridades superiores de cualquier delito perpetrado en su jurisdicción realizando las primeras diligencias si tenían cabida en sus facultades.

Por último, los alcaldes y tenientes de alcalde contaban con capacidad para imponer multas que debían ser cobradas en papel del Estado ${ }^{71}$, y dirigidas mensualmente a los jueces del partido ${ }^{72}$. En caso de que los multados fuesen insolventes, el alcalde podía decretar prisión no superior a dos días y si la infracción mereciese penas severas mayores de las que el alcalde estaba facultado, éste estaba obligado a instruir sumario y enviarlo al juez competente ${ }^{73}$. Las multas, al igual que la posibilidad de enviar a alguien a la cárcel constituían los dos principales instrumentos de sanción con los que contaban los alcaldes y se insertaban en la vertiente judicial de su poder. A éstos medios se añadían las competencias sobre el aprovisionamiento y mantenimiento de las cárceles, asociadas a su vertiente de delegado del gobierno en los pueblos. En este sentido el alcalde era responsable no solo de las condiciones de vida de los presos, sino también del mantenimiento del edificio y el sustento de los presos sin recursos propios para pagar su estancia en la cárcel.

\subsection{FUNCIONES DERIVADAS DEL CARÁCTER ELECTIVO DE SU PODER}

\section{A) Organización del ayuntamiento y ejecución de sus acuerdos}

La Ley de 1845 establecía que todos los asuntos debían tratarse en dos reuniones semanales de carácter ordinario, y si por alguna razón, quedaban asuntos pendientes, se podría convocar una sesión con carácter extraordinario y urgente, bajo la responsabilidad del alcalde ${ }^{74}$. Las convocatorias eran tarea del alcalde mediante cédulas personales con acuse de recibo y en las que se especificaba el orden del día. Una vez convocada una reunión no se podían tratar más temas que los preestablecidos en la cédula de convocatoria y cualquier desvío de esta norma provocaba la anulación de la sesión y la responsabilidad del alcalde ${ }^{75}$. El alcalde respondía directamente ante el jefe político/gobernador y cualquier incidente o problema debía ser comunicado al mismo para impedir que se aprobase el acta en la sesión siguiente ${ }^{7}$.

Como presidente del ayuntamiento debía nombrar a los miembros del mismo, presidir su juramento y organizarlos en comisiones ordinarias de trabajo. En esta labor el alcalde se perfilaba como gran conocedor de los individuos del municipio, así como gran componedor de equilibrios, para que las comisiones de trabajo contasen con representantes de todos los grupos de interés del municipio ${ }^{77}$.

El alcalde dirigía las sesiones, vigilaba los acuerdos y era responsable de la ejecución de los mismos, de modo que si los consideraba peligrosos, o estaba disconforme con los mismos, podía revocarlos dando noticia inmediata

$71 \quad$ Real Orden del 30 abril de 1851, Gaceta de Madrid del 1 de mayo de 1851, № 6135. Existía papel especial para ello en poder de recaudadores y debían ser entregados cumplimentados en las tesorerías de los ayuntamientos.

72 Los alcaldes tenían facultades para imponer multas de cuantía diversa en función de la población: En los pueblos de menos de 500 vecinos podían imponer hasta 100 reales en los pueblos de menos de 5.000 vecinos hasta 300 reales y en los pueblos superiores a esa población podían cobrar hasta 500 reales

73 En la consulta al Consejo Real relativa a las atribuciones del alcalde para imponer arrestos, se hizo por un expediente de competencias entre el Jefe Político de Toledo y el Juez de Primera Instancia de Escalona sobre procedimientos contra el Alcalde de Almorox. Ante el desacuerdo de competencias fue consultado el Consejo Real quien se pronunció a favor del particular. En la causa un vecino de Almorox fue requerido por el alcalde para que presentase licencia para escopeta. Éste no lo hizo y el alcalde le multó con 100 reales o 5 días de cárcel. El vecino escogió los 5 días de cárcel y estuvo preso 4 días en el ayuntamiento. El juez formó causa al alcalde por esta actuación, pues entendía que sus competencias se limitaban a poner multas. El jefe político defendió al alcalde diciendo que no se había extralimitado sino que había sido el vecino el que había elegido y la cuestión llegó al Consejo Real. El Consejo Real analizó la parte de la Constitución de 1845 donde se decía que tan solo tribunales y juzgados podían proceder a la averiguación de delitos y a su castigo y le prohibió a los alcaldes extralimitarse. Por otra cuestión se consultó al Consejo Real sobre la imposición de una multa en Valladolid y de ahí se desprendió que visto el Art. 106 del reglamento de los juzgados de primera instancia de 1 de mayo de 1844 los alcaldes y sus tenientes tan solo podían actuar como delegados y auxiliares de los jueces respectivos y subordinados a los mismos en las diligencias que aquellos practicasen.

74 Ley de organización y atribuciones de los ayuntamientos del 8 de enero de 1845, Título IV, Art. 61-69.

75 La legislación progresista de 1823 preveía que se celebrase al menos una sesión ordinaria a la semana y si superaba los 1.000 habitantes debían hacerse dos sesiones ordinarias y a puerta abierta publicando las fechas de antemano a principios de año. Se requería la reunión de al menos la mitad más uno de los concejales y no se necesitaba convocatoria expresa del alcalde ya que se publicaba desde inicios de año. Sin embargo, las reuniones extraordinarias sí necesitaban la convocatoria del alcalde, y requerían de un protocolo específico.

76 Un ejemplo de los problemas que ocasionaba la complejidad de la legislación lo encontramos en el acta de sesiones del Ayuntamiento de Santiago de Compostela del 18 de noviembre de 1853 cuando Nicolás García Vázquez se negó a aprobar el acta de la sesión anterior, firmada ya por todos los regidores, porque no deseaba que en ésta constase que había sido pedida y convocada por algunos concejales y no por el alcalde. De esta manera, la sesión quedó consignada en el acta, pero no fue aprobada, siendo necesario repetir todos los acuerdos. AHUS, Actas Consistoriales, sesión del 18 de noviembre de 1853.

77 PÉREZ RODRÍGUEZ, A. C. (2012). Pág. 308-375. 
razonada al jefe político/gobernador ${ }^{78}$.

Como administrador del pueblo el alcalde presidía las subastas y remates de arriendos confiriendo validez a estos actos públicos, otorgaba escrituras de compra-venta, arrendamiento o cualquier otro tipo de operación para la cual el ayuntamiento contase con competencias, vigilaba a los recaudadores y a los empleados del ramo y actuaba como representante del pueblo en juicios ${ }^{79}$.

\section{B) La gestión económica del ayuntamiento}

El alcalde tenía a su cargo la elaboración del presupuesto municipal anual y aunque su capacidad de influencia en el mismo era considerable, las partidas denominadas "obligatorias", estaban comprometidas de antemano por la legislación emanada del Gobierno. Como presidente del ayuntamiento tan solo podía intervenir dando preferencia a unos gastos sobre los otros y tipificar los gastos consignados en las partidas "voluntarias" 80.

Una vez formalizado el presupuesto, era sometido a los filtros de la corporación y del jefe político/gobernador. La documentación contable y presupuestaria del Ayuntamiento de Santiago de Compostela correspondiente al período 1845-1868 demuestra que la revisión del presupuesto por el ayuntamiento fue siempre un mero trámite y nunca se rechazaron los presupuestos. Hay que mencionar sin embargo, que los regidores a cambio de no rechazar los presupuestos solían conseguir que se cambiaran ciertos arbitrios por otros que les eran menos gravosos para sus negocios y que sin embargo lo eran para colectivos que no estaban representados en el ayuntamiento ${ }^{81}$.

El gobernador, decidía sobre los presupuestos cuando contaban con unos ingresos inferiores a 200.000 reales y si los superaban tras evaluarlos y mandar hacer las rectificaciones, los enviaba al Gobierno. Entre 1845 y 1868 el presupuesto del Ayuntamiento de Santiago de Compostela fue devuelto numerosas veces por motivos varios como: no especificar las partidas, no incluir los capítulos que el Gobierno establecía para temas muy precisos y sobre todo, por molestar a ciertas actividades comerciales protegidas por el Gobierno, imponiéndoles arbitrios sobre los productos con los que comerciaban o tenían actividad industrial.

Además de la formación del presupuesto, el alcalde contaba con capacidad para realizar los pagos, pero para ello tenía que asegurarse que los gastos se imputaban a partidas aprobadas en sesión ordinaria. Junto al Depositario, eran los responsables de que ninguna cantidad saliese de las arcas municipales sin haber sido autorizada primero y que además quedase consignada en los registros de gasto. Por su parte, el apartado de imprevistos era más flexible, pero tampoco podía hacer uso de ese dinero sino informaba previamente y conseguía su aprobación.

Por último, el alcalde elaboraba las cuentas anuales de gastos, las cotejaba con las realizadas por el depositario y ambas eran revisadas y aprobadas por la corporación y el jefe político/gobernador.

Las competencias económicas del alcalde lo enfrentaban no solo con la corporación municipal sino también con los mayores contribuyentes. Era frecuente que los contribuyentes que se sentían agraviados por las decisiones del ayuntamiento le enviasen exposiciones conjuntas quejándose de su gestión económica, de la falta de claridad en la recaudación de las contribuciones, de la preferencia de unas zonas del municipio frente a otras para realizar obras municipales, de la injusticia de los repartimientos frente a otras poblaciones, etc. La ley estipulaba que el alcalde y la comisión de contabilidad realizaban los informes pertinentes y era el ayuntamiento al completo el que resolvía el expediente y las quejas ${ }^{82}$.

78 "Para evitar que las providencias gubernativas dictadas por los ayuntamientos y diputaciones provinciales dentro del límite de sus facultades, puedan anularse recurriendo a la autoridad judicial para pedir amparo en la posesión ó restitución por el que se diga despojado ; y á fin de que no se reproduzcan con este motivo los graves y perjudiciales y las administrativas, oído el supremo tribunal de justicia y conforme con su parecer se ha declarado por punto general que las disposiciones y providencias que dicten los ayuntamientos y en su caso las diputaciones provinciales, en los negocios que pertenecen a sus atribuciones según las leyes, forman estado y deben llevarse a efecto, sin que los tribunales admitan contra ellas los interdictos posesorios de manutención o restitución aunque deberán administrar justicia a las partes cuando entablen las otras acciones que legalmente les competan". R.O. 8 de mayo de 1839.

79 Art. 74 de la Ley de Organización y Atribuciones de los ayuntamientos del 8 de enero de 1845 .

80 Art. 94 de la Ley de Organización y Atribuciones de los ayuntamientos del 8 de enero de 1845.

81 Un ejemplo de los diferentes intereses que se encontraban en los ayuntamientos a causa de los ingresos, lo encontramos en el presupuesto del Ayuntamiento de Santiago de 1849 cuando la corporación, apoyada por el gobernador, rechazó el borrador porque no eran partidarios de los arbitrios elegidos para cubrir las necesidades presupuestarias. El alcalde alegaba la inexistencia de otras formas de cubrir el déficit que ocasionaban los gastos más indispensables de la ciudad, pero el gobernador ordenó elaborar otro presupuesto y encontrar arbitrios menos gravosos para el comercio.

82 El ayuntamiento estaba profundamente endeudado y los comerciantes de la ciudad prestaron dinero al ayuntamiento para amueblar la casa del Capitán General Juan de Villalonga. En esta sesión es el alcalde el que actúa de portavoz de los comerciantes reclamando el dinero que se le adeuda ante el ayuntamiento, el cual le autoriza a que haga un inventario del material comprado y las cuentas de su coste, ayudado por el veedor. AHUS, Fondo municipal, Actas Consistoriales, sesión del 24 de mayo de 1847. 


\section{C) Competencias en materia de personal}

La ley le otorgaba al alcalde capacidad para ampliar o disminuir la plantilla de trabajadores del ayuntamiento, proponer o retirar nombres de las listas de ternas, despedir o nombrar personal, aumentar o disminuir el sueldo de los empleados, etc. Estas prerrogativas no eran aplicables a todos los funcionarios ${ }^{83}$ del ayuntamiento, pero si a los que según la ley de 1845 ocupaban los puestos de los ramos de policía urbana y rural, es decir todo lo que tuviese que ver con orden público y seguridad ciudadana. Las partidas económicas dedicadas a estas funciones eran las más dotadas según podemos comprobar en la tabla correspondiente al Ayuntamiento de Santiago de Compostela.

TABLA 1. PRESUPUESTO DE GASTOS DEL AYUNTAMIENTO DE SANTIAGO DE COMPOSTELA.

\begin{tabular}{|l|l|l|l|l|l|l|}
\hline & 1845 & 1850 & 1855 & 1860 & 1865 & $1867-68$ \\
\hline ADMINISTRACIÓN & 48.721 & 70.394 & 62.296 & 74.606 & 96.555 & 90.120 \\
\hline POLICÍA SEGURIDAD & 1.460 & 79.340 & 81.530 & 81.165 & 98.522 & 100.710 \\
\hline POLICÍA URBANA & 22.500 & 56.180 & 73.920 & 96.283 & 117.950 & 135.410 \\
\hline INSTRUCCIÓN PÚBLICA & 9.386 & 24.593 & 40.675 & 33.650 & 60.275 & 82.240 \\
\hline BENEFICENCIA & 83.464 & 60.000 & 183.670 & 235.454 & 405.278 & 418.380 \\
\hline OBRAS PÚBLICAS & 25.500 & 108.786 & 21.460 & 47114 & 151.210 & 45.380 \\
\hline CORRECCIÓN PUBLICA & & 1.000 & 20.500 & 22.000 & 36.365 & 38.830 \\
\hline CARGAS VARIAS & & 24.588 & 14.588 & 264.735 & 111.443 & 67.590 \\
\hline GASTOS IMPREVISTOS & 3.000 & 10.000 & 8.000 & 25.654 & 20.000 & 20.000 \\
\hline
\end{tabular}

Elaboración propia a partir de los presupuestos municipales entre 1845 y $1868^{84}$.

La tabla permite comprobar que el alcalde manejaba de facto dos grandes partidas del capítulo de gastos, la de policía urbana y la de policía de seguridad. La mayor parte de estas cantidades estaban dedicadas a pagar los sueldos de los empleados de ambos ramos, de modo que los de seguridad se llevaban un total del $44,4 \%$ de lo presupuestado para esta partida y los de policía urbana un 10,4\% de la suya ${ }^{85}$.

TABLA 2. LOS EMPLEADOS DEL AYUNTAMIENTO DE SANTIAGO DE COMPOSTELA

\begin{tabular}{|c|c|c|c|c|}
\hline OFICIO & NOMBRE & NOMBRAMIENTO & $\begin{array}{l}\text { AUTORIDAD } \\
\text { NOMBRAMIENTO }\end{array}$ & SUELDO \\
\hline Macero & Pedro Suárez y Antonio López & $1 / 01 / 1864$ & Alcalde & $80^{\circ}$ \\
\hline Escribano & Manuel Pardo & $24 / 06 / 1863$ & Alcalde & 160 \\
\hline Alguacil & Angel Garcia y Bernardino Cisneros & $2 8 \longdiv { 0 6 \longdiv { 1 8 6 6 } }$ & Alcalde & 1.090 \\
\hline Guarda alameda & Pedro do Campo & $01 / 02 / 1862$ & Alcalde & 1.460 \\
\hline Tambor & Antonio Seiio & $25 / 06 / 1862$ & Alcalde & 1.460 \\
\hline cantero & Ramón González & $01 / 06 / 1854$ & Alcalde & 1820 \\
\hline Peón & $\begin{array}{c}\text { Andrés Moscoso, José Rey y Fico. } \\
\text { Ríos }\end{array}$ & $01 / 10 / 1854$ & Alcalde & 1820 \\
\hline Cantero & José Barros y Pedro Villaverde & $03 / 02 / 1856$ & Alcalde & 1820 \\
\hline Peón & Manuel Rivas y José Aguiar & $0 3 \longdiv { 0 2 / 1 8 5 6 }$ & Alcalde & 1820 \\
\hline Cabo & José Arcay & $16 / 01 / 1854$ & Alcalde & 1820 \\
\hline Peón & Fco.Válcarcel González & $2 5 \longdiv { 0 6 \longdiv { 1 8 6 6 } }$ & Alcalde & 1.820 \\
\hline Municipal & Manuel Míguez & $01 / 04 / 1854$ & Alcalde & 2.190 \\
\hline Municipal & Ramon Nêira & $0 1 \longdiv { 0 1 / 1 8 6 3 }$ & Alcalde & 2.190 \\
\hline Municipal & Francisco Mourelle & $09 / 01 / 1865$ & Alcalde & 2.190 \\
\hline Municipal & José García Gómez & $1 4 \longdiv { 0 5 / 1 8 6 5 }$ & Alcalde & 2.190 \\
\hline Municipal & $\begin{array}{c}\text { José Gómez, Juan Villar y Domingo } \\
\text { Puente }\end{array}$ & $17 / 07 / 1858$ & Alcalde & 2.190 \\
\hline Municipal & José María Martínez y José Sangenis & $22 / 02 / 1848$ & Alcalde & 2.190 \\
\hline Municipal & Cayetano Costoya & $2 6 \longdiv { 0 6 \longdiv { 1 8 6 5 } }$ & Alcalde & 2.190 \\
\hline Municipal & Andrés Otero & $31 / 07 / 1865$ & Alcalde & 2.190 \\
\hline Escribiente & Eugenio Ferreiro & $01 / 07 / 1860$ & Alcalde & 2.550 \\
\hline $\begin{array}{l}\text { Inspector } \\
\text { caminos }\end{array}$ & Pedro Villahoz & $26 / 04 / 1865$ & Ayuntamiento & 2.000 \\
\hline Alguacil & Antonio Fernández & $16 / 10 / 1855$ & Ayuntamiento & 2.200 \\
\hline Veedor & Angel Troncoso & $29 / 12 / 1858$ & Aýuntamiento & 2.200 \\
\hline
\end{tabular}

83 Los términos empleado y funcionario se empleaban indistintamente hasta que en 1869 pasaron a ser definidas como el primero como "el destinado por el Gobierno al servicio público" y como "empleado público" en el caso del funcionario. Ver FERNÁNDEZ SEBASTIÁN, J.; FUENTES, J.F. (2002).

84 Las cantidades están en reales.

85 El gasto en los empleados de urbana supone un porcentaje más bajo porque en esta partida iban incluidos los gastos de alumbrado que al ser muy grandes, hacían menos representativa la cuantía dedicada a los sueldos. 


\begin{tabular}{|c|c|c|c|c|}
\hline Alguacil & Francisco López Vigo & $08 / 05 / 1852$ & Ayuntamiento & 2.220 \\
\hline Portero & Manuel Vicente & $01 / 01 / 1863$ & Ayuntamiento & 2.560 \\
\hline Sereno & José lglesias & $01 / 05 / 1859$ & Ayuntamiento & 2.730 \\
\hline Sereno & Antonio Puentes & $01 / 06 / 1855$ & Ayuntamiento & 2.730 \\
\hline Sereno & Francisco López y Segundo Martín & $0 1 / 0 8 \longdiv { 1 8 5 5 }$ & Ayuntamiento & 2.730 \\
\hline Sereno & Benito Reboredo y Francisco Mato & $01 / 11 / 1833$ & Ayuntamiento & 2.730 \\
\hline Sereno & Jacobo Méndez & $0 1 \longdiv { 1 2 / 1 8 5 4 }$ & Ayuntamiento & 2.730 \\
\hline Sereno & Domingo Balsa & $03 / 011860$ & Ayuntamiento & 2.730 \\
\hline Sereno & Antonio Taibo & $0 4 \longdiv { 0 3 / 1 8 3 4 }$ & Ayuntamiento & 2.730 \\
\hline Sereno & Andrés López & $08 / 03 / 1862$ & Ayuntamiento & 2.730 \\
\hline Sereno & Pedro Otero & $01 / 11 / 1833$ & Ayuntamiento & 2.730 \\
\hline Sereno & Tomás Peiteado & $11 / 03 / 1864$ & Ayuntamiento & 2.730 \\
\hline Sereno & José Domínguez & $1 4 \longdiv { 0 3 / 1 8 5 8 }$ & Ayuntamiento & 2.730 \\
\hline Sereno & Francisco Reboredo & $1 4 \longdiv { 0 3 / 1 8 6 5 }$ & Ayuntamiento & 2.730 \\
\hline Sereno & Francisco Couselo & $1 4 \longdiv { 0 4 / 1 8 5 2 }$ & Ayuntamiento & 2.730 \\
\hline Sereno & $\begin{array}{l}\text { José Sueiro, Manuel Rivas, Domingo } \\
\text { Calvo, Manuel Noya, Domingo Paz, } \\
\text { Jacobo Tarrio }\end{array}$ & $16 / 02 / 1861$ & Ayuntamiento & 2.730 \\
\hline Cabo & Antonio Bernardino Rey & $18 / 08 / 1855$ & Ayuntamiento & 2.730 \\
\hline Sereno & Pedro Suárez & $0 2 / 0 2 \longdiv { 1 8 5 7 }$ & Ayuntamiento & 2.730 \\
\hline Sereno & Manuel Prado & $2 0 / 1 2 \longdiv { 1 8 5 3 }$ & Ayuntamiento & 2.730 \\
\hline Sereno & Antonio Peteiro & $2 1 / 0 4 \longdiv { 1 8 5 4 }$ & Ayuntamiento & 2.730 \\
\hline Sereno & José Rey Saravia & $23 / 01 / 1865$ & Ayuntamiento & 2.730 \\
\hline Sereno & Pedro Rey y José Pena & $2 3 \longdiv { 0 6 } 1 8 3 8$ & Ayuntamiento & 2.730 \\
\hline Sereno & Domingo Cea & $2 7 \longdiv { 1 2 \longdiv { 1 8 4 0 } }$ & Ayuntamiento & 2.730 \\
\hline Sereno & Jorge Lafuente & $2 7 \longdiv { 1 2 / 1 8 4 0 }$ & Ayuntamiento & 2.730 \\
\hline Sereno & Pedro Almeira & $28 / 04 / 1852$ & Ayuntamiento & 2.730 \\
\hline Sereno & Salvador Budiño y José Rivas & $3 1 0 3 \longdiv { 1 8 4 6 }$ & Ayuntamiento & 2.730 \\
\hline Oficial $3^{\circ}$ & Eduardo Vázquez & $1 8 \longdiv { 0 7 1 8 6 6 }$ & Ayuntamiento & 3.500 \\
\hline Capataz & Antonio Montes & $1 9 \longdiv { 0 9 \longdiv { 1 8 5 6 } }$ & Ayuntamiento & 3.900 \\
\hline 1 capataz & Jose Ulloa Varela & $1 4 \longdiv { 0 6 / 1 8 5 5 }$ & Ayuntamiento & 4.400 \\
\hline Oficial $2^{\circ}$ & Regino Borobio & $1 8 / 0 7 \longdiv { 1 8 6 6 }$ & Ayuntamiento & 4.800 \\
\hline Oficial $1^{\circ}$ & Tomás Gonzalez & $18 / 071866$ & Ayuntamiento & 5.000 \\
\hline Médico & Juan Ramón Barcia & $18 / 11 / 1863$ & Ayuntamiento & 8.000 \\
\hline Arquitecto & Manuel de Prado y Vallo & $2506 / 1840$ & Ayuntamiento & 8.000 \\
\hline Secretario & Eugenio de la Riva & $0 7 \longdiv { 1 2 / 1 8 4 7 }$ & Ayuntamiento & 12.000 \\
\hline Depositario & Fermín Rodríguez & $15 / 12 / 1853$ & Ayuntamiento & 12.200 \\
\hline $\begin{array}{l}\text { Maestro } \\
\text { elemental }\end{array}$ & Gabriel Cabezas & $24 / 03 / 1866$ & $\begin{array}{c}\text { Dirección Gal. instruc. } \\
\text { pública }\end{array}$ & 6.600 \\
\hline Auxiliar & Ventura del Río y Lorenzo & $12 / 02 / 1851$ & $\begin{array}{c}\text { Junta prov. instruc. } \\
\text { pública }\end{array}$ & 6.600 \\
\hline $\begin{array}{l}\text { Maestro } \\
\text { elemental }\end{array}$ & Manuela Fandiño & $15 / 09 / 1853$ & Junta prov. Instrucc.pub & 4.400 \\
\hline $\begin{array}{l}\text { Regente } \\
\text { primero }\end{array}$ & Andrés Jacinto Suárez & $07 / 09 / 1849$ & $\begin{array}{c}\text { Junta prov.instruc. } \\
\text { pública }\end{array}$ & 7600 \\
\hline $\begin{array}{l}\text { Maestro } \\
\text { elemental }\end{array}$ & Fortunato Rodríguez & $01 / 08 / 1862$ & Rector universidad & 5.000 \\
\hline
\end{tabular}

Elaboración propia a partir de las Actas Consistoriales 1845-1868.

- La diferencia de sueldo entre los distintos empleados públicos no sólo obedecía a la cualificación y posición del empleo sino también a que muchos eran contratados como interinos para sustituir a empleados que estaban enfermos o como ayudantes de los mismos y compartían el sueldo del titular.

A pesar de que tan sólo nombraba tan sólo a 37 de los 82 oficios públicos que tenemos registrados entre 1845 y 1868 , el alcalde mantenía bajo su control no solo a la policía urbana y rura ${ }^{86}$ sino también a las autoridades que la auxiliaban: comisarios celadores y agentes de protección de seguridad pública ${ }^{87}$. Hasta junio de 1845 todos ellos contaban con capacidad para imponer multas, pero desde esa fecha esta competencia fue reservada a los alcaldes $^{88}$. El alcalde podía actuar en asuntos de policía urbana como el control estadístico de las personas, la concesión de licencias, pasaportes y demás referencias personales, la sanidad de calles y del consumo y lo referente a urbanismo. La importancia de los temas de policía urbana quedó reflejada cuando el Ministerio de Gobernación creó en 1852 una Junta Consultiva de Policía Urbana dependiente directamente del Ministerio y con capacidad para resolver las consultas de los pueblos sobre estos temas, proponer mejoras en las ordenanzas municipales y vigilar los proyectos de urbanismo ${ }^{89}$. El desarrollo urbanístico producido en los años cincuenta incrementó las tareas del alcalde sobre estas cuestiones, sobre todo en lo que a alineación y salubridad se refería, reforzando el

86 Art. 74 de la Ley de ayuntamientos de 1845.

87 Real Orden del 30 de enero de 1844.

88 Real Orden del 30 de mayo de 1845, Gaceta de Madrid del 7 de junio de 1845, N 3919.

89 Real Orden del 11 de agosto de 1852, Gaceta de Madrid del 12 de agosto de $1852, N^{\circ} 6625$. 
papel gubernativo del presidente del Consistorio ${ }^{90}$.

El alcalde ostentaba la jefatura superior de la plantilla municipal pero normalmente seguía la tónica de sus antecesores acerca del número y los sueldos de los empleados y tan solo aumentaban la plantilla si resultaba estrictamente necesario o les reportaba algún beneficio91. El control de los trabajadores, en lo referido a sueldos y provisión de plazas, les otorgaba una posición significativa para conformar y mantener clientelas políticas y monopolizar la administración a favor de grupos de poder ${ }^{92}$.

\section{D) Recaudación de contribuciones y formalización de estadísticas}

El alcalde tenía a su cargo el cobro de las contribuciones estatales y provinciales donde actuaba como delegado gubernamental, y las contribuciones municipales donde tenía un marcado carácter de gestor público y representante del pueblo.

Las contribuciones estatales y provinciales eran fijadas por el Gobierno y la diputación, por lo tanto las tareas del alcalde respecto a ellas se limitaban a recibir las reales órdenes donde se detallaban las cuantías y los procedimientos a seguir para la recaudación, informar al ayuntamiento y facilitar el cobro de las mismas. En lo que respecta a los impuestos municipales, el alcalde debía esforzarse mucho más porque determinaba los arbitrios a recaudar, encargaba las propuestas de tipos y presidía las subastas de arbitrios.

Como representante de los pueblos, realizaba un estudio sobre la productividad de cada arbitrio propuesto en la lista ofrecida por el Gobierno con el objeto de determinar los menos gravosos para los vecinos y para las actividades económicas con más influencia en el municipio. Una vez elegidos los arbitrios, eran aprobados por la corporación y enviados al jefe político/gobernador para la revisión de las especies gravadas, los tipos y los productos que se le calculaban. La actuación del alcalde en la elección de arbitrios era fundamental no sólo porque debía equilibrar las distintas actividades económicas evitando grabar al comercio más que a la industria por ejemplo, sino también porque dentro de cada grupo debía elegir los productos que resultasen menos gravosos al conjunto de la población. El filtro a posteriori de la corporación debía resolver cualquier problema que se plantease, pero en muchos casos las propuestas de arbitrios fueron devueltas por el Gobierno porque encarecían excesivamente los productos de primera necesidad y empobrecían las condiciones de vida de los más desfavorecidos y sobre todo porque arruinaban determinados sectores comerciales a la vez que favorecían a otros.

El alcalde, al igual que el resto de la corporación, no intervenían en la recaudación de los arbitrios, sino que la ley determinaba que éstos fuesen cobrados con los consumos y en el caso santiagués siempre se utilizaba como método recaudatorio el arrendamiento a empresarios particulares ${ }^{93}$. Como representante del pueblo y de sus intereses, el alcalde presidía las subastas de arrendamiento tratando de obtener el mejor precio posible porque de ello dependía el grueso de los ingresos fijados en el presupuesto municipal.

En su papel de gestoreconómico supervisaba las actuaciones dela comisión de recaudaciones del ayuntamiento, la marcha de la recaudación, el ingreso mensual del producto en la Depositaría y por último autorizaba los pagos mensuales al arrendatario descontados del total recaudado. Estas responsabilidades garantizaban la ejecución del presupuesto y evitaban los apremios de Hacienda sobre los miembros de la corporación que respondían en última

90 Desde 1848 las actuaciones de los alcaldes en el mejoramiento de las infraestructuras son palpables. Debemos mencionar la actuación del alcalde Miguel Díaz en la sesión del 31 enero de 1848, poco después de su nombramiento, en la que manifiesta que quiere mejorar las calles y ordena a la comisión de obras públicas la elaboración de un informe sobre el estado de las vías públicas y el presupuesto necesario para reconstruir las que estén deterioradas Este alcalde destacará por dos cosas por un lado su gran preocupación por mejorar la infraestructura de la ciudad y sus comunicaciones exteriores con Lugo y Orense, pero por otro lado su corta duración en el puesto (es destituido a los cuatro meses de ser nombrado) dejarán estos proyectos para fines de la década de los cincuenta.

91 En 1855 el Ayuntamiento de Santiago redujo los sueldos de todos los empleados entre cuatro y dos reales, según la categoría, alegando la falta de recursos en el presupuesto municipal. Lo ahorrado en los sueldos se dedicó a obras públicas, pero a cambio se aumentaron también las partidas de milicia urbana. Al regresar los moderados al poder se eliminó la milicia urbana y se aumentaron los sueldos de los empleados. Según el presupuesto de 1855 al primer capataz se le rebaja de 14 a 10 reales diarios, al segundo de 10 a 7 , los serenos pasan a cobrar 6 reales diarios en vez de siete. En el ramo de policía urbana el capataz veedor pasa a cobrar 7 reales diarios en vez de 8 inicialmente asignados, los guardias municipales son reducidos a la mitad quedando solo cinco, los dependientes de limpieza también se reducen. AHUS, Fondo municipal, Actas Consistoriales de 1855.

92 Como ejemplo podemos citar la sesión de 25 de marzo de 1854 donde el alcalde comunica al ayuntamiento que ya había consignado en el presupuesto municipal la necesidad de cuatro guardias municipales más y que era necesario nombrarlos y darles uniforme. El alcalde en esta sesión no solo consigue que se declaren en propiedad los que ya venían haciendo el trabajo como suplentes, sino que además sea incluido un cantero escogido por el, con la excusa de que en los días normales de trabajo hiciese reparaciones pequeñas en las calles y durante los días festivos hiciese el mismo servicio que los demás. En la misma sesión sin dar ningún tipo de razón suspende a un trabajador del ayuntamiento y nombra a otra persona para el mismo puesto, sin pasar por la votación del ayuntamiento ni tampoco una proposición formal AHUS, Fondo municipal, Actas Consistoriales, sesión del 25 de marzo de 1854. ver sobre este tema KETTERING, S. (1988).; EINSENSTADT, S.N; RONIGER, L. (1970).

93 La ley le ofrecía la posibilidad de recaudar el ayuntamiento por si mismo estos impuestos pero cada año los miembros del consistorio y los mayores contribuyentes determinaban en reunión conjunta que la recaudación se hiciese vía arrendatario. 
instancia con su patrimonio. Los apremios no solo desgastaban el prestigio del municipio y sus representantes, sino que ocasionaban enormes gastos porque las dietas de un comisionado de apremio eran muy onerosas y eran costeadas enteramente por el municipio contra el que se enviaba94.

Por último, el alcalde actuaba como gestor económico al ejecutar acciones de gobierno que beneficiaban claramente a los mayores contribuyentes a los que representaba. En este sentido trataba de conseguir siempre que las estadísticas poblacionales y de riqueza fuesen lo más alejadas posible de la realidad. La forma de manejar este asunto era el nombramiento de los miembros de las comisiones de estadística, tanto las que elaboraban los datos de población como las que recababan las referencias económicas para la imposición de contribuciones. Era de interés del municipio que no hubiese un conocimiento real de la población ni de su riqueza, dado que en función de ella se establecían los cupos del ejército, y que tampoco se contase con referencias fiables sobre cada contribuyente, porque a mayor riqueza del pueblo, mayor cupo le tocaba repartir95. La revisión de los padrones y de las fuentes fiscales utilizados para la imposición de cuotas nos ha permitido concluir que los errores y las omisiones en las estimaciones de riqueza respondían no solo a los intereses personales de cada contribuyente, sino también a un interés real del poder municipal para rebajar los índices de riqueza del conjunto de la población ${ }^{96}$.

\section{E) Fomento de la propiedad pública e infraestructura}

Los alcaldes hacían grandes esfuerzos por la conservación de bienes del común asignándoles una gran parte del presupuesto. El patrimonio municipal lo componían las fincas de su propiedad, los edificios dedicados a almacenes públicos, las alhóndigas, mercados, plazas de abastos, mataderos, cárceles, hospicios, establecimientos de beneficencia, teatros, aguas, tierras, pastos, caza y cualquier tipo de aprovechamiento del común de los $v^{v e c i n o s}{ }^{97}$. Estas propiedades constituían lo que se llamaban los "propios” y la misión del alcalde era administrarlos y obtener el mejor rendimiento posible. En el panorama español convivían ayuntamientos con muchos recursos de propios con otros como el Ayuntamiento de Santiago de Compostela que contaba con muy pocos bienes de este tipo.

TABLA 3. INGRESOS DEL AYUNTAMIENTO DE SANTIAGO DE COMPOSTELA

\begin{tabular}{|c|c|c|c|c|c|}
\hline & 1845 & 1850 & 1855 & 1860 & 1865 \\
\hline PROPIOS & 1.529 & 1.109 & 1.109 & 957 & 1.400 \\
\hline ARBITRIOS & 296.652 & 408.129 & 19.285 & 50.392 & 40.000 \\
\hline BENEFICENCIA & 0 & 0 & 99.670 & 151.454 & 309.043 \\
\hline CORRECCIÓN PÚBLICA & 0 & 0 & 0 & 0 & 17.125 \\
\hline ARBITRIOS EXTRAORDINARIOS & 0 & 26.430 & 0 & 8.248 & 219.694 \\
\hline
\end{tabular}

Elaboración propia a partir de los presupuestos municipales AHUS, Fondo Municipal presupuestos municipales 1845-1868.

Los ingresos obtenidos por el Ayuntamiento de Santiago de su propio patrimonio fueron disminuyendo progresivamente, no solo en cuantía, sino también en importancia real frente a los restantes ingresos, porque los cada vez mayores gastos son pagados con la imposición de nuevos arbitrios ${ }^{98}$. Los "propios" del ayuntamiento consistían en unas pocas fincas en el centro de la ciudad que estaban arrendadas a los vecinos lo que condicionaba sus ingresos y sus tácticas presupuestarias ${ }^{99}$. El ayuntamiento carecía de montes de su propiedad y los puestos públicos que arrendaba en el mercado (alhóndiga y pescadería) contaban como arbitrios ya que anualmente se subastaba su explotación. La falta de patrimonio centraba la atención del alcalde en cuidar de los bienes muebles, uniformes y material de trabajo de los empleados municipales así como la propiedad simbólica y cultural del ayuntamiento. Estas pertenencias al ser propiedad del ayuntamiento evitaban gastos de arrendamientos pero

94 Real Decreto 24 julio 1850, Gaceta de Madrid, $n^{\circ}$ 5855. Se establece que en adelante se harían primero los apremios a los mayores contribuyentes y luego a los restantes debido a lo costoso que resultaban los comisionados de apremio al dilatar mucho en el tiempo su trabajo para cobrar mayores dietas y porque los primeros contribuyentes requerían un trato distinto por sus condiciones distintas.

95 Sobre los quintas y el sistema de reclutamiento militar podemos consultar BORREGUERO, C. (1989). La autora afirma que los pueblos utilizaban todo tipo de triquiñuelas para evitar que sus mozos se enrolasen en el ejército, utilizando incluso a malhechores y vagabundos para cubrir los cupos y entregarlos al Estado.

96 ARTOLA GALLEGO, M. (1986).; COMIN COMIN, F. (1988).; FUENTES QUINTANA, E. (1990).; SALORT I VIVES, S. (1998).

97 Los bienes de propios son asimilados con el patrimonio municipal. Ver ESTAPÉ RODRíGUEZ, F. (1969). Carmen García equipara los bienes de propios con las propiedades que tenía un determinado municipio y que podía gestionar por sí mismo sin necesidad de permiso. Ver GARCÍA GARCÍA, C. (1986). Pág 89-113.

98 Antonio Bernal define los propios como bienes rústicos y urbanos a los que en ocasiones se asimilan rentas, censos y juros. Ver BERNAL, A. M. (1978). Pág. 285-312.

99 La escasez de propios ya se daba en el siglo XVIII y en el XIX no pudo incrementarse. Ver CEBREIROS ÁLVAREZ, E. (1999). 
tenían la contrapartida de no producir riqueza ${ }^{100}$.

El alcalde tenía una autoridad limitada sobre las propiedades municipales, ya que debía cuidarlos e incrementarlos pero para venderlos o repararlos necesitaba un permiso del jefe político/gobernador ${ }^{101}$. La falta de competencias no afectaba a los bienes muebles, donde se pueden encontrar grandes inversiones en útiles simbólicos y artículos de lujo por parte los alcaldes en momentos de gran endeudamiento del municipio ${ }^{102}$.

\section{F) Dirección de los establecimientos de instrucción pública y beneficencia}

El papel del alcalde era insustituible para la gestión de la instrucción pública, ya que como administrador de los pueblos dirigía, financiaba y promocionaba estos establecimientos. El Estado se desentendía totalmente de la educación primaria pública en el sentido de la financiación y la organización, reservándose un papel exclusivo de controlador de contenidos ${ }^{103}$. La ley de $1845^{104}$ dejaba en manos del alcalde la búsqueda de recursos económicos con los que mantener las escuelas, organizar y presidir las juntas que vigilarían su funcionamiento ${ }^{105}$, promocionar la prensa y la difusión de libros que fomentasen la cultura, desarrollar las academias, asociaciones científicas y actividades culturales encaminadas a hacer desaparecer los altos índices de analfabetismo ${ }^{106}$. Además la ley les reservaba la misión de garantizar la educación de los niños con menores recursos. Su obligación consistía en conseguir que éstos no faltasen a la escuela y sus padres fuesen conscientes de la necesidad y la importancia de la escolarización, lo que sin duda no constituía una tarea sencilla en una sociedad que veía a los niños como productores de recursos para la familia desde temprana edad ${ }^{107}$.

El alcalde consignaba anualmente las cantidades necesarias para financiar las escuelas y mantener sus edificios y ordenaba trimestralmente su pago al Depositario municipal. En caso de necesidades especiales, como las reparaciones o compras extraordinarias de materiales escolares, se recurría a la imposición de arbitrios especiales poco gravosos y consensuados con los mayores contribuyentes.

En lo concerniente a la beneficencia, los establecimientos como hospitales, hospicios, casas de misericordia, casas de expósitos, casas de dementes, socorros públicos para los más desfavorecidos, Montes de Piedad y asociaciones de socorros mutuos, eran también objeto de la vigilancia de los alcaldes. Para poder controlar todos estos centros se constituyeron juntas municipales de beneficencia que informaban periódicamente al

100 No todos estos bienes producían riqueza, sino que algunos como los uniformes o los útiles de trabajo suponían gastos cada dos o tres años porque debían ser renovados por el ayuntamiento. Sin embargo suponían bienes propios en los inventarios de riqueza y un descuento en los sueldos de los empleados porque se les daba todo el material a cambio de salarios bajos. Son frecuentes las quejas de los guardias nocturnos, los tambores, veedores, celadores de cuartel, etc. quejándose cada dos años de que no se les renueva el uniforme como estaba pactado por convenio o que sus capas no protegen del frío y humedad por estar raídas, además de producir socarronería en el vecindario que les niega el respeto por ir vestidos con harapos, etc.

101 El alcalde propone al ayuntamiento reparar los muebles de la sala de sesiones por un total de 33.652 reales, pero ante la escasez de dinero para pagarlo propone contratar un préstamo especial autorizado por el gobernador. El asunto a pesar de tener autorización se demora mucho en el tiempo solucionándose a mediados de la década de los sesenta, ya que el ayuntamiento está profundamente endeudado con particulares y se encuentra también apremiado por Hacienda pública debido a los retrasos en el pago de la Derrama. AHUS, Fondo municipal, Actas Consistoriales, sesión 1 mayo de 1857.

102 Para ello el alcalde no necesitaba contar con la autorización de su inmediato superior pero sí cuidar sus actuaciones y comparecencias al igual que las de su equipo ante los ciudadanos. Un ejemplo es la compra de dos candelabros de plata propuestos por el alcalde en 1865 y aprobados por el ayuntamiento. Los candelabros costaron 9.196 reales y son adquiridos muy poco después de aprobar un presupuesto con un déficit de 510.000 reales, lo que según nuestros parámetros constituye un lujo incomprensible. El alcalde lo justificó como un asunto de imagen y lo consideró tan importante que ni siquiera consigna el gasto en el presupuesto sino que compra inmediatamente y hace el pago del capítulo de imprevistos, quedando el ayuntamiento absolutamente desamparado ante cualquier eventual contratiempo. Este mismo alcalde, Benito Amor Labrada, propone adquirir también un bastón de presidente para el individuo que ejerciese de alcalde en las ceremonias "porque no era justo que al pasar la alcaldía a los señores tenientes o regidores tuviesen que adquirirlo por el corto tiempo que la ejerciesen”. AHUS, Fondo municipal, Actas Consistoriales sesión del 21 de junio de 1865.

103 Un ejemplo de sus actuaciones fue la unificación ortográfica en un mismo libro: Prontuario de Ortografía, publicado por la Real Academia y que fue obligatorio por Real Decreto de 28 de abril de 1844 y luego por Real Decreto del 6 de enero de 1845 . Ver Gaceta de Madrid del 7 de enero de 1845, $\mathrm{N}^{\circ}$ 3768. Otros ejemplos son el Diccionario de la lengua castellana, La gramática de la lengua castellana, El Tratado de Ortografía, etc., todos ellos publicados por la Real Academia Española.

104 Hay que tener en cuenta que era únicamente en las etapas moderadas y bajo la ley de 1845 que el alcalde tenía las prerrogativas de control de la enseñanza primaria, pues bajo las leyes progresistas de 1823 (Instrucción de 3 de febrero de 1823) eran las comisiones locales de Instrucción primaria las que se encargaban de todo lo referente a ésta y también de su control.

105 Estas juntas vigilaban e inspeccionaban las escuelas públicas determinando las condiciones de los establecimientos, métodos de enseñanza que se empleaban, formación religiosa, moral e intelectual de los niños, asistencia de estos, etc.

106 Plan General de Instrucción Primaria del 21 de julio de 1838.

107 A veces, teoría y práctica no iban de la mano como ocurrió en la escuela de Santo Domingo de Santiago de Compostela donde un maestro estuvo en su puesto durante cincuenta años castigando físicamente a los niños y descuidando su formación intelectual con conocimiento del ayuntamiento y sin que ningún equipo municipal hiciese nada por solventar el problema. Cuando el maestro se retiró a pesar de los informes negativos sobre su comportamiento se le concedió una pensión cuantiosa en pago a los servicios a pesar de que se reconocía que habían sido deficientes. 
ayuntamiento y le preparaban los temas sobre los que debía votar ${ }^{108}$.

La ley del 6 de febrero de 1822 encargó por primera vez la dirección de la beneficencia pública a las juntas municipales en calidad de auxiliares de los ayuntamientos, pero éstas solo desempeñaron este cometido en los períodos progresistas. La ley de 1845 prescindió de las juntas municipales y responsabilizó directamente a los alcaldes de los establecimientos municipales de beneficencia. Ello provocó numerosos conflictos entre ambas instituciones hasta que el Real Decreto de Instrucción Pública de 1846 entregó definitivamente todos los poderes sobre beneficencia al alcalde, quedando las juntas como meros entes consultivos ${ }^{109}$.

Las funciones del alcalde respecto a la beneficencia consistían en la formación del presupuesto para estos establecimientos, la búsqueda de recursos para financiarlos, la contratación y vigilancia del personal que prestaba servicios en éstos y la sensibilización social sobre la necesidad de estos lugares y su mantenimiento por los poderes públicos municipales.

\section{CONCLUSIONES}

Como hemos visto a lo largo de este artículo, el alcalde moderado era una figura insustituible, dotada de amplias competencias y fundamental para la estabilidad de los pueblos y el orden social. Los moderados consiguieron hacer del alcalde el fiel reflejo del jefe político/gobernador en la provincia y reproducir el esquema piramidal de gobierno que ya se venía fraguando desde el Trienio Liberal y que consiguieron instalar definitivamente.

El alcalde no sólo era el jefe del ejecutivo en el ayuntamiento, sino que representaba al mismo y servía de correa de transmisión en la jerarquía administrativa dibujada por la administración liberal. Desde el punto de vista de las competencias actuaba en el mantenimiento del orden y la salud pública, el control de los recursos económicos de los pueblos y el desarrollo institucional de los mismos a través del control de la instrucción pública, la beneficencia o la gestión municipal. El alcalde controlaba las elecciones, presionaba a los mayores contribuyentes, ejercía de muro de contención contra las aspiraciones de las clases populares a través de sus competencias en materia de orden público y garantizaba en definitiva el funcionamiento de la maquinaria administrativa y recaudadora de impuestos que constituían los ayuntamientos.

Todos estos poderes, aunque amplios, se veían matizados por el principio de jerarquía administrativa a la que estaban sometidos tanto el alcalde como los ayuntamientos. La estructura jerárquica actuó positivamente sobre el asentamiento de los ayuntamientos como estructura básica administrativa local pero por otra parte ralentizó extremadamente su funcionamiento y la gestión ordinaria de los asuntos locales.

\section{BIBLIOGRAFIA} XXI.

AJA, E. y SOLÉ TURA, J. (1988). Constituciones y períodos constituyentes en España (1808-1936), Madrid, Siglo

ARTOLA GALLEGO, M. (1986). La Hacienda del siglo XIX: progresistas y moderados, Madrid, Alianza.

BERNAL, A. M. (1978). "Haciendas locales y tierras de propios: Funcionalidad económica de los patrimonios municipales (siglos XVI-XIX)" en Hacienda Pública española, №. 55, Madrid. Pp. 285-312.

BORREGUERO, C. (1989). El reclutamiento militar por quintas en al España del siglo XVIII. Orígenes del servicio militar obligatorio. Universidad de Valladolid, Valladolid.

CABALLERO, M. (1994). El sufragio censitario, elecciones generales en Soria durante el reinado de Isabel. Madrid, Junta de Castilla y León.

CAJAL VALERO, A. (1999). El Gobernador civil y el estado centralizado del siglo XIX, Madrid, Ministerio de administraciones públicas.

CARASA SOTO, P. (1991). Historia de la beneficencia en Castilla y León: poder y pobreza en la sociedad castellana, Secretariado de publicaciones, Valladolid, Universidad de Valladolid.

CEBREIROS ÁLVAREZ, E. (1999). El municipio de Santiago de Compostela a finales del Antiguo Régimen (17591812), Santiago de Compostela, Xunta de Galicia.

108 Estaba compuesta por el alcalde como presidente, un regidor, el cura párroco más antiguo, cuatro vecinos, un médico y un cirujano de los de mayor reputación. Uno de los vocales de la junta desempeñaba las funciones de secretario y otro de contador, elegidos por la junta y aprobados por el ayuntamiento. Sus funciones eran proponer primero a las personas más adecuadas para la administración de los centros y luego vigilar que cumpliesen sus obligaciones, proponer los arbitrios para mantenerlos y examinar sus cuentas,

109 Real Decreto del 5 de abril de 1846, Art. 5. Gaceta de Madrid del 4 de abril de $1846, \mathrm{~N}^{\circ} 4220$. 
COMIN COMIN, F. (1988). Hacienda y economía en la España contemporánea (1800-1936), Madrid.

EINSENSTADT, S.N; RONIGER, L. (1970). Patron-client relations as a model of structuring social exchange". In Comparative Sudies in society and history, Vol 22, $\mathrm{N}^{\circ}{ }^{1}$. Pp. 42-77.

ESTAPÉ RODRíGUEZ, F. (1969). "Propios y arbitrios” en Diccionario de historia de España, Madrid.

FERNÁNDEZ CASANOVA, M.C. (2001). "Instituciones fiscales y comerciantes en Galicia, 1824-1834, el ejemplo de Santiago, en FERNÁDEZ CASANOVA, C. (Edit.): Comerciantes y artesanos, Sémata, № 12. Pp 67-91.

FERNÁNDEZ CASANOVA, M.C. (2011). El trabajo en la ciudad. Diccionario de profesiones de las ciudades de Galicia 1845-1924, Madrid, Consejo Superior de Investigaciones Científicas.

FERNÁNDEZ SEBASTIÁN, J.; FUENTES, J.F. (2002). Diccionario político y social del siglo XIX español, Madrid, Alianza Editorial.

FONT DE MORA, T. (1991). "La preparación de la Constitución de 1845", Revista de Estudios Políticos, (Nueva época), $N^{\circ} 73$, julio-septiembre. Pp. 229-241.

FORNER MUÑOZ, S. y GARCÍA ANDREU, M. (1990). Cuneros y caciques, Alicante, Patronato del V centenario. Crítica.

FUENTES QUINTANA, E. (1990). Las reformas tributarias en España: teoría, historia y propuestas, Barcelona,

GARCÍA GARCÍA, C. (1986). "Haciendas municipales y bienes de propios: las reformas de Carlos III", en Anales de Estudios Económicos y Empresariales, № 1, Valladolid.

GONZÁLEZ ARES, J. (1981). Las constituciones de España, Madrid, Taurus.

GONZÁLEZ ARES, J.A. (1997). Introducción al estudio del Constitucionalismo español (1808-1975), Santiago, Tórculo.

GONZÁLEZ CASANOVA, J. A. (1986). Las diputaciones provinciales en España. Historia política de las Diputaciones desde 1812 hasta 1985, Madrid.

IGLESIAS OTERO, M.L Y PÉREZ RODRÍGUEZ, A.C. (2001). "Consideraciones generales sobre la actividad comercial en Santiago a través de la documentación de arbitrios y consumos (1845-principios del siglo XX)" en FERNÁNDEZ CASANOVA, C., Comerciantes y artesanos, SÉMATA, N 12. Pp. 93-108.

KETTERING, S. (1988). "The Historical Development of Political Clientelism", Journal of Interdisciplinary History, XVIII: 3. Pp. 419-447.

MARCUELLO BENEDICTO, J.I. (1986). La práctica parlamentaria en el reinado de Isabel II, Madrid, Publicaciones del Congreso de los Diputados.

MAZA ZORRILLA, E. (1999). Pobreza y beneficencia en la España contemporánea (1808-1936), Barcelona, Ariel.

MORELL OCAÑA, L. (1977). "Un precedente: el Jefe Político y Diputaciones Provinciales en la Constitución de 1812” en El Gobernador civil en la política y en la administración de la España contemporánea, Madrid, Ministerio del Interior. Pp.131-157.

MORILLO-VELARDE, J.I. (1977). El alcalde en la Administración Española. Instituto García Oviedo, Sevilla.

OLIVÁN Y BORRUEL, A. (1843). De la administración pública con relación a España, Boix Editor, Madrid.

OLLERO VALLÉS, J.L. (2006). "Las culturas políticas del progresismo español: Sagasta y los puros" en SUÁREZ CORTINA, M. La redención del pueblo, la cultura progresista en la España liberal, Santander, Universidad de Cantabria. Pp 239-269.

PÉREZ RODRÍGUEZ, A.C. (2012). Administración, gestión y poder político en el Ayuntamiento de Santiago de Compostela 1845-1868. Tesis doctoral, A Coruña, http: //hdl . handle . net/2183/10058 .

PÉREZ RODRíGUEZ, A.C. (2014). "La búsqueda de los orígenes de la administración municipal: de la Edad Media al Liberalismo”, Revista de la Administración Local y Autonómica, (Nueva Época), REALA, nº 1, enero-junio. Pág. 52-66.

RUEDA HERNANZ, G. (2006). España 1790-1900. Sociedad y condiciones económicas, Madrid, Istmo.

SALORT I VIVES, S. (1998). La hacienda local en la España contemporánea: la hacienda municipal de Alacant 18001923, Alacant, Institut de cultura "Juan Gil -Albert". 
SÁNCHEZ AGESTA, L. (1984). Historia del constitucionalismo español, Madrid, Instituto de Estudios Políticos.

SANTANA MOLINA, M. (1989). La Diputación Provincial en la España decimonónica, Madrid, Instituto Nacional de Administración Pública.

SOLÉ TURA, J. (1975). Introducción al régimen político español, Barcelona, Ariel.

TOMÁS VILLARROYA, J. (1981). Breve historia del Constitucionalismo español, Madrid, Centro de Estudios Constitucionales. 